OPEN ACCESS

Edited by:

Hongyue Dang,

Xiamen University, China

Reviewed by:

Marta Salgueiro Alves,

University of Aveiro, Portugal

Zhe-Xue Quan,

Fudan University, China

${ }^{*}$ Correspondence:

Shuili Yu

ys/@tongji.edu.cn

Lei Li

lilei@tongji.edu.cn

Specialty section: This article was submitted to

Aquatic Microbiology,

a section of the journal

Frontiers in Microbiology

Received: 09 July 2017 Accepted: 27 November 2017 Published: 12 December 2017

Citation:

Li Q, Yu S, Li L, LiU G, Gu Z, Liu M, Liu Z, Ye Y, Xia Q and Ren L (2017)

Microbial Communities Shaped by Treatment Processes in a Drinking Water Treatment Plant and Their Contribution and Threat to Drinking Water Safety. Front. Microbiol. 8:2465. doi: 10.3389/fmicb.2017.02465

\section{Microbial Communities Shaped by Treatment Processes in a Drinking Water Treatment Plant and Their Contribution and Threat to Drinking Water Safety}

\section{Qi Li, Shuili Yu*, Lei Li*, Guicai Liu, Zhengyang Gu, Minmin Liu, Zhiyuan Liu, Yubing Ye, Qing Xia and Liumo Ren}

State Key Laboratory of Pollution Control and Resource Reuse, College of Environmental Science and Engineering, Tongji University, Shanghai, China

Bacteria play an important role in water purification in drinking water treatment systems. On one hand, bacteria present in the untreated water may help in its purification through biodegradation of the contaminants. On the other hand, some bacteria may be human pathogens and pose a threat to consumers. The present study investigated bacterial communities using Illumina MiSeq sequencing of 16S rRNA genes and their functions were predicted using PICRUSt in a treatment system, including the biofilms on sand filters and biological activated carbon (BAC) filters, in 4 months. In addition, quantitative analyses of specific bacterial populations were performed by real-time quantitative polymerase chain reaction (qPCR). The bacterial community composition of post-ozonation effluent, BAC effluent and disinfected water varied with sampling time. However, the bacterial community structures at other treatment steps were relatively stable, despite great variations of source water quality, resulting in stable treatment performance. Illumina MiSeq sequencing illustrated that Proteobacteria was dominant bacterial phylum. Chlorine disinfection significantly influenced the microbial community structure, while other treatment processes were synergetic. Bacterial communities in water and biofilms were distinct, and distinctions of bacterial communities also existed between different biofilms. By contrast, the functional composition of biofilms on different filters were similar. Some functional genes related to pollutant degradation were found widely distributed throughout the treatment processes. The distributions of Mycobacterium spp. and Legionella spp. in water and biofilms were revealed by realtime quantitative polymerase chain reaction (qPCR). Most bacteria, including potential pathogens, could be effectively removed by chlorine disinfection. However, some bacteria presented great resistance to chlorine. qPCRs showed that Mycobacterium spp. could not be effectively removed by chlorine. These resistant bacteria and, especially potential pathogens should receive more attention. Redundancy analysis (RDA) showed 
that turbidity, ammonia nitrogen and total organic carbon (TOC) exerted significant effects on community profiles. Overall, this study provides insight into variations of microbial communities in the treatment processes and aids the optimization of drinking water treatment plant design and operation for public health.

Keywords: microbial community, Illumina MiSeq sequencing, function prediction, drinking water treatment processes, aquatic pathogens, chlorine resistant bacterial populations

\section{INTRODUCTION}

Bacteria play an important role in water treatment. On one hand, bacteria from untreated water can utilize organic and inorganic matters as growth substrates, resulting in enhanced biological stability and lower levels of micropollutants in water (Lautenschlager et al., 2013; Hedegaard and Albrechtsen, 2014). On the other hand, some may be potential human pathogens, such as some Legionella (Berjeaud et al., 2016) and Mycobacterium species (Vaerewijck et al., 2005). Making full use of bacterial biodegradation and controlling pathogens are thus two major goals in drinking water treatment.

Biofiltration, one of the oldest water treatment methods, is designed to encourage bacterial growth on granular materials to enable biodegradation (Proctor and Hammes, 2015). Biofiltration processes (e.g., rapid sand, granular activated carbon (GAC), and slow sand filtration) are categorized according to their support materials and operation modes. Sand and GAC filtration are the most popular methods, and are regarded as conventional and advanced treatments, respectively. Biofiltration performance depends on stable bacterial community structures and high microbial activity (Fonseca et al., 2001; Kim et al., 2014), but treatment processes and their configurations usually cause variations in the bacterial community (Zeng et al., 2013; Prest et al., 2016). The bacterial communities present in treatment systems were mainly introduced by the source water (Yang et al., 2011). In general, the first two treatments applied to source water are flocculation and sedimentation that do not significantly change the microbial community structure (Lin et al., 2014). This is followed by sand filtration. The bacterial community found in the sand filters is modulated by the bacteria present in the sedimentation effluent ( $\mathrm{Xu}$ et al., 2017). GAC filtration usually comes next, most of the times combined with ozone which constitutes an ozone-biological activated carbon $\left(\mathrm{O}_{3}-\mathrm{BAC}\right)$ treatment process. Ozone oxidizes natural organic matters, forming easily biodegradable, lowmolecular-weight by-products, and increases dissolved oxygen (DO) concentrations. Ozone is thus positively correlated with the growth of microorganisms on GAC (Yang et al., 2016). However,

Abbreviations: BAC, Biological Activated Carbon; qPCR, Quantitative Polymerase Chain Reaction; RDA, Redundancy Analysis; TOC, Total Organic Carbon; $\mathrm{O}_{3}-\mathrm{BAC}$, Ozone-Biological Activated Carbon; DO, Dissolved Oxygen; NGS, Next Generation Sequencing; PICRUSt, Phylogenetic Investigation of Communities by Reconstruction of Unobserved States; OTUs, Operational Taxonomic Units; ACE, Abundance-based Coverage Estimator; PCoA, Principal Coordinate Analysis; ANOVA, Analysis of Variance; KEGG, Kyoto Encyclopedia of Genes and Genomes; NSTI, Nearest Sequenced Taxon Index; NMDS, Nonmetric Multidimensional Scaling; PERMANOVA, Permutational Multivariate Analysis of Variance. ozone, as a powerful oxidant, can also effectively inactivate bacteria (Hunt and Marinas, 1999). The effect of ozonation on bacterial communities therefore deserves further research, which will facilitate evaluating the influence of ozonation on BAC filtration.

Biofiltration effectively removes biodegradable compounds. However, biofilms colonized on filter materials can slough off, shaping the subsequent bacterial community (Pinto et al., 2012; Lautenschlager et al., 2014) and increasing bacterial populations in the effluent (Stewart et al., 1990; Zhang et al., 2015). Bacteria released from BAC filters are extremely resistant to disinfection (Camper et al., 1986; Yu et al., 2014). Disinfection, the final step of water treatment, is critical to control the microbiome released into the treated water and inhibit microbial growth during distribution. However, disinfection cannot completely destroy the microbiome in treatment plants and thus potentially acts as a stress-based selective pressure (Gomez-Alvarez et al., 2012; Holinger et al., 2014; Wang et al., 2014). The bacteria selected by disinfectants should receive more attention.

Several physicochemical water parameters, as $\mathrm{pH}$, temperature, dissolved organic carbon, etc., were described to influence the bacterial community dynamics (Lindstrom, 2000; Li et al., 2010; Pinto et al., 2012; Kim et al., 2014; Staley et al., 2015). Understanding the correlation between water quality parameters and bacterial communities could help trace changes in microbiome by monitoring water quality parameters. Seasonal changes cause great variations in water quality indices ( $\mathrm{Li}$ et al., 2014; Feng et al., 2016). However, only a few studies investigated the bacterial community structure in a water treatment plant across the four seasons (Pinto et al., 2012). To study the microbiome structure and diversity, culture-independent methods allow deeper analysis than the culture-dependent ones. The advantage of its long reads once led 454 pyrosequencing to be widely used on drinking water samples (Pinto et al., 2012; Zeng et al., 2013; Kim et al., 2014; Lautenschlager et al., 2014; Lin et al., 2014). However, 454 pyrosequencing has a higher per-base error rate and is susceptible to indel errors in homopolymer stretches (Loman et al., 2012). Therefore, 454 pyrosequencing has been discontinued with the development of next-generation sequencing (NGS) (Tan et al., 2015). Illumina MiSeq technology has become increasingly popular due to its advantages of lower cost, greater throughput and higher accuracy (Hirai et al., 2017). However, applications of Illumina MiSeq sequencing to drinking water remain scarce (LaPara et al., 2015). As different sequencing platforms are generally discrepant (Smith and Peay, 2014; Sinclair et al., 2015), the adoption of new sequencing platforms for drinking water samples is of paramount significance. In addition, phylogenetic 


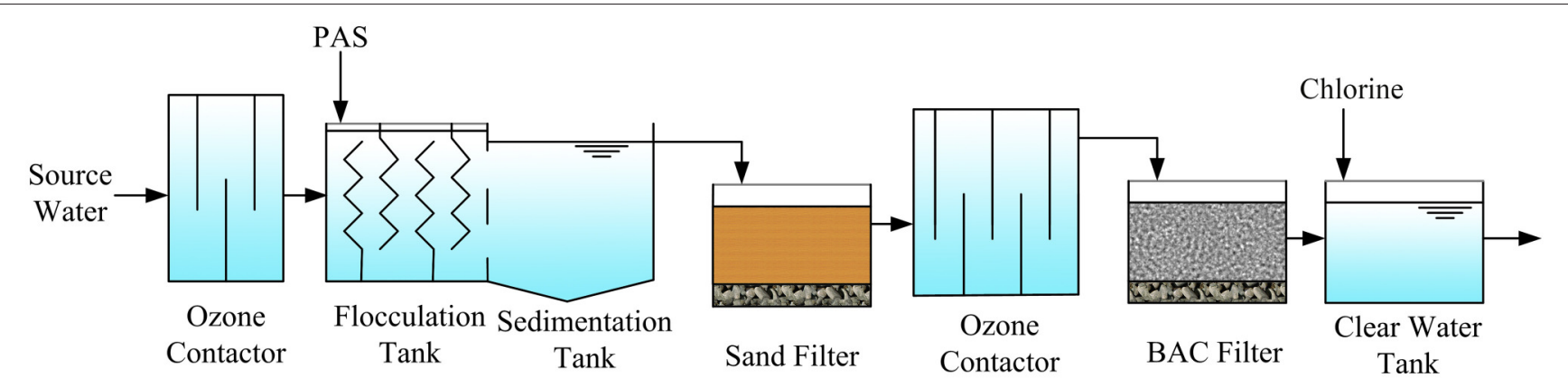

FIGURE 1 | Schematic diagram of the drinking water treatment plant (PAS, polyaluminium sulfate).

investigation of communities by reconstruction of unobserved states (PICRUSt), a new computational approach, enables predicting the functional composition of bacterial communities using 16S rRNA marker gene sequences (Langille et al., 2013). In contrast to the qualitative analysis of high-throughput sequencing, the real-time quantitative polymerase chain reaction (qPCR) is a useful tool for the quantitative tracking of specific bacterial strains (Brinkman et al., 2003). The integration of high-throughput sequencing with $\mathrm{qPCR}$ is thus beneficial for assessing the composition of microbial communities, especially for detecting specific bacteria.

The primary objective of this study was to analyze the variations in bacterial communities and functional profiles during treatment processes to determine the role bacteria play in water treatment. Illumina MiSeq sequencing was applied to identify and characterize bacterial communities in a drinking water treatment plant that features conventional and advanced biofiltration processes. To clarify seasonal influence in the bacterial community structure, sampling was carried out at each process step over one year. The obtained $16 \mathrm{~S}$ data were processed using PICRUSt 1.0.0 to predict the functions of microbial communities. Bacteria from the genera Mycobacterium and Legionella, which include human pathogens, were quantified using qPCR. In addition, the water quality parameters were measured over the sampling year to access to their influence on the bacterial communities. The proper adjustment of the water quality parameters would allow a better control and management of the bacterial community structures over the drinking water treatment systems.

\section{MATERIALS AND METHODS}

\section{Drinking Water Treatment Processes}

The drinking water treatment plant is located in Wujiang District, Suzhou, Jiangsu Province, China $\left(31.11^{\circ} \mathrm{N}, 120.62^{\circ} \mathrm{E}\right)$. The source water originated from the eastern Lake Taihu, the third largest freshwater lake in China. Lake Taihu has been experiencing eutrophication problems for several decades. The average water quality of Lake Taihu is ranked as class IV (class IV, the best to the worst), according to the Environmental Quality Standard for Surface Water of China. The samples were taken from the eastern part of Lake Taihu, where the water quality is the best in the lake. This plant produces nearly $300,000 \mathrm{~m}^{3} /$ day drinking water. The source water was successively treated by preozonation, flocculation, sedimentation, sand filtration, postozonation, BAC filtration and chlorine disinfection (Figure 1). Appropriate amounts of free chlorine were added to the BAC effluent to secure free residual chlorine levels above 0.4 $\mathrm{mg} / \mathrm{L}$ after $30 \mathrm{~min}$ of contact time. At the preozonation step, $0.5 \mathrm{mg} / \mathrm{L}$ ozone is added with a contact time of $5 \mathrm{~min}$, while $1 \mathrm{mg} / \mathrm{L}$ ozone is added with a $12 \mathrm{~min}$ contact time for postozonation.

\section{Sampling, Sample Processing and Physico-chemical Analysis}

The sampling campaign was conducted during 4 months (November, January, May and July) from 2015 to 2016. Each of the 4 months belonged to a different season (fall, winter, spring and summer, respectively). Water samples were taken in triplicate from each water treatment step in $1 \mathrm{~L}$ sterile bottles. BAC and sand media were collected from the upper and middle parts of filter beds in $5 \mathrm{~mL}$ sterile sample tubes. Three sampling spots were randomly selected each time that the filters were sampled. The upper biofilm samples were collected from the surface of filters. The middle biofilm samples were collected at a depth of $0.5-0.8 \mathrm{~m}$. All the samples were transported on ice to the laboratory and processed within $12 \mathrm{~h}$. Each water sample was carefully pooled with its three replicates. Then, $0.5 \mathrm{~L}$ of surface water, $2 \mathrm{~L}$ of disinfected water and $1 \mathrm{~L}$ of each for the remaining water samples were filtered through $0.22 \mu \mathrm{m}$ nitrocellulose membranes $(50 \mathrm{~mm}$ diameter, Millipore, USA). Three replicate biofilm samples from each part of filters were carefully pooled. The filter membranes and mixed biofilm media were stored at $-80^{\circ} \mathrm{C}$ before DNA extraction.

Temperature, $\mathrm{pH}$ and DO were measured immediately after water sampling at each sampling site using an HQ30d portable multi-parameters water quality analyzer (Hach, USA). Ammonia nitrogen, nitrite and nitrate were analyzed according to standard protocols (APHA, 2011). Turbidity was determined using a $2100 \mathrm{~N}$ turbidity analyzer (HACH, USA). Total organic carbon (TOC) was measured using an Aurora 1030W TOC analyzer (OI, USA). 
TABLE 1 | Water quality parameters of source water and treated water at each sampling time.

\begin{tabular}{|c|c|c|c|c|c|c|c|c|}
\hline $\begin{array}{l}\text { Sample by type } \\
\text { and date }\end{array}$ & Temperature $\left({ }^{\circ} \mathrm{C}\right)$ & $\mathrm{pH}$ & Turbidity (NTU) & DO (mg/L) & TOC (mg/L) & $\begin{array}{c}\text { Nitrate } \\
\left(\mathrm{mg} / \mathrm{L}, \text { as } \mathrm{NO}_{3}^{-}\right)\end{array}$ & $\begin{array}{l}\text { Nitrite }(\mathrm{mg} / \mathrm{L} \text {, as } \\
\left.\qquad \mathrm{NO}_{2}^{-}\right)\end{array}$ & $\begin{array}{l}\text { Ammonia (mg/L, as } \\
\left.\mathrm{NH}_{3}^{-} \mathrm{N}\right)\end{array}$ \\
\hline \multicolumn{9}{|l|}{ RAW WATER } \\
\hline Nov. & 16.7 & 7.83 & 10.7 & 9.30 & 4.97 & 0.76 & 0.038 & 0.46 \\
\hline Jan. & 6.2 & 8.13 & 12.5 & 12.36 & 4.26 & 0.82 & 0.035 & 0.48 \\
\hline May & 20.3 & 7.76 & 26.1 & 7.7 & 8.26 & 0.72 & 0.043 & 0.44 \\
\hline Jul. & 28.6 & 7.68 & 19.4 & 6.32 & 8.55 & 1.53 & 0.042 & 0.40 \\
\hline \multicolumn{9}{|c|}{ TREATED WATER } \\
\hline Nov. & 16.5 & 7.51 & 0.23 & 10.16 & 2.61 & 0.81 & No detected ${ }^{\mathrm{a}}$ & 0.06 \\
\hline Jan. & 6.8 & 7.46 & 0.30 & 12.34 & 2.50 & 0.78 & 0.003 & 0.05 \\
\hline May & 20.1 & 7.43 & 0.25 & 9.03 & 3.68 & 0.91 & No detected ${ }^{\mathrm{a}}$ & 0.03 \\
\hline Jul. & 28.3 & 7.25 & 0.28 & 7.26 & 3.38 & 1.68 & 0.002 & 0.07 \\
\hline
\end{tabular}

${ }^{a}$ No Detected: below the detection limit.

\section{DNA Extraction, PCR Amplification and Sequencing}

The filtered membranes with collected biomass were cut into pieces with sterilized scissors, and total DNA was extracted using an E.Z.N.ATM Mag-Bind Soil DNA Kit (OMEGA, USA) following the manufacturer's protocol. Appropriate biofilm samples ( $0.5 \mathrm{~g}$ of BAC samples and $2 \mathrm{~g}$ of sand samples) were subjected to DNA extraction using this kit. The bacterial V3-V4 region of the 16S rRNA gene was amplified using the forward primer $341 \mathrm{~F}$ (5'-CCCTACACGACGCTCTTCCGATCTG-3') and the reverse primer $805 \mathrm{R}\left(5^{\prime}\right.$-GACTGGAGTTCCTTGGCA CCCGAGAATTCCA-3'). PCR amplification was performed by a $\mathrm{T} 100^{\mathrm{TM}}$ Thermal Cycler (BIO-RAD, USA). All PCR reactions were performed in triplicate with $20 \mu \mathrm{L}$ of the final reaction mixture, which contained $4 \mu \mathrm{L}$ of $5 \times$ Fast Pfu Buffer, $2 \mu \mathrm{L}$ of $2.5 \mathrm{mM}$ dNTPs, $0.8 \mu \mathrm{L}$ of each primer $(5 \mu \mathrm{M}), 0.4 \mu \mathrm{L}$ of Taq DNA Polymerase (Thermo Scientific, USA), $0.2 \mu \mathrm{L}$ BSA, and $10 \mathrm{ng}$ of template DNA. The thermal cycling conditions were as follows: an initial denaturation step at $95^{\circ} \mathrm{C}$ for $3 \mathrm{~min}$, and 28 cycles at $95^{\circ} \mathrm{C}$ for $30 \mathrm{~s}, 55^{\circ} \mathrm{C}$ for $30 \mathrm{~s}$, and $72^{\circ} \mathrm{C}$ for $45 \mathrm{~s}$, followed by a final extension at $72^{\circ} \mathrm{C}$ for $10 \mathrm{~min}$ (Shu et al., 2016). PCR products were initially screened using $2 \%$ agarose gels and purified using Agencourt AMPure XP (Beckman, USA) according to the instructions. Purified PCR products were paired-end sequenced on the Illumina MiSeq platform (Illumina, USA) at a read length of $2 \times 300 \mathrm{bp}$. In total, 44 samples were sequenced at the Sangon Biotech (Shanghai) Co. Ltd.

The 16S rRNA gene sequences were deposited in the NCBI Sequence Read Archive under accession number SRP106506.

\section{Real-Time Quantitative PCR (qPCR) Analysis for Potential Pathogens and Total Bacteria}

Legionella spp. Mycobacterium spp. and total bacteria were enumerated by qPCR using an ABI7500 Real-Time PCR System (Life Technologies, USA). For Legionella spp., a PCR strategy was designed to amplify the Legionella genus-specific 23S rRNA gene, using the forward primer $5^{\prime}$-CCCATGAAGCCCGTTGAA-3' and the reverse primer
$5^{\prime}$-ACAATCAGCCAATTAGTACGAGTTAGC-3', with the $5^{\prime}$ HEX-TCCACACCTCGCCTATCAACGTCGTAGT-TAMRA-3' TaqMan probe (Nazarian et al., 2008). The PCR program was as follows: $95^{\circ} \mathrm{C}$ for $30 \mathrm{~s}$, and 40 cycles at $95^{\circ} \mathrm{C}$ for $5 \mathrm{~s}$ and $58.5^{\circ} \mathrm{C}$ for $34 \mathrm{~s}$.

Mycobacterium spp. were quantified by targeting $16 \mathrm{~S}$ rRNA gene using the forward primer (5'CCTGGGAAACTGGGTCTAAT- $\left.3^{\prime}\right)$, the reverse primer $\left(5^{\prime}\right.$-CGCACGCTCACAGTTA- $\left.3^{\prime}\right)$ and probe (5'-FAMTTTCACGAACAACGCGACAAACT-TAMRA-3') (Radomski et al., 2010). The PCR program was as follows: $95^{\circ} \mathrm{C}$ for $30 \mathrm{~s}$, and 45 cycles at $95^{\circ} \mathrm{C}$ for $5 \mathrm{~s}, 55^{\circ} \mathrm{C}$ for $15 \mathrm{~s}$ and $72^{\circ} \mathrm{C}$ for $34 \mathrm{~s}$. Total bacteria were quantified using the forward primer $(1369 \mathrm{~F}$ : CGGTGAATACGTTCYCGG) and the reverse primer (1492R: GGWTACCTTGTTACGACTT) with an annealing temperature of $55^{\circ} \mathrm{C}$ (Suzuki et al., 2000).

qPCR reactions were performed in triplicate with each $10-\mu 1$ reaction mixture containing $5 \mu \mathrm{l}$ of $2 \times$ Premix Ex Taq, $200 \mathrm{nM}$ each primer, $100 \mathrm{nM}$ probe, $0.1 \mu \mathrm{l}$ of $50 \times \mathrm{ROX}$ as a reference dye and $1 \mu \mathrm{l}$ of DNA template. Control reactions contained the same mixtures, but with $1 \mu \mathrm{l}$ of sterile water replacing the DNA template. The standard DNA were prepared and run during each qPCR to generate standard curves $\left(r^{2}>0.99\right)$. Amplification efficiency was monitored and standards amplified with similar efficiencies (91-99\%, depending on the assay).

\section{Sequence Processing and Data analysis}

The sequence data were processed to trim the reads with a $Q_{\text {phred }}$ score below 20 using QIIME (Caporaso et al., 2010). Adapters were removed using cutadapt (Chen et al., 2014). Trimmed paired-end reads were merged with a maximum mismatch rate of 1 mismatch in 10 bases using PEAR (Unno, 2015). Then sequences were demultiplexed using QIIME. And the quality filtering was performed using Prinseq (Schmieder and Edwards, 2011) to remove homopolymers longer than $8 \mathrm{bp}$ and sequences less than $200 \mathrm{bp}$, showing ambiguous base "N" or with average base quality score less than 20. UCHIME software was used to identify and remove chimeras (Edgar et al., 2011). All samples were normalized to ensure an equal number of sequences in each 

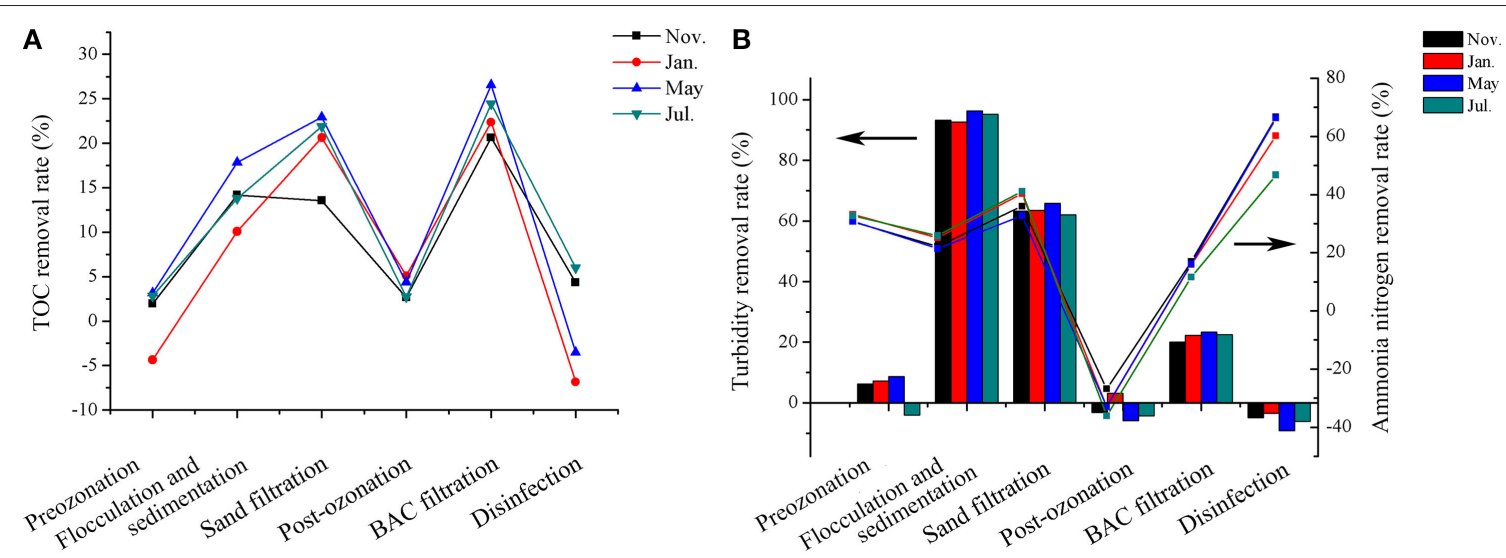

FIGURE 2 | Variations in removal rates of TOC (A), turbidity (left axes, histogram) and ammonia nitrogen (right axes, line graph) (B) along the treatment processes at different times. The arrows in the figure indicated the corresponding vertical coordinate of different data.

sample by random subsampling for further analyses. Operational Taxonomic Units (OTUs) were clustered with a 97\% similarity cutoff using Usearch (Edgar, 2010) and classified against the Ribosomal Database Project (RDP) dataset with a confidence level cutoff of $80 \%$ (Cole et al., 2009). Sequences flagged as chloroplasts, mitochondria, or eukaryotes (accounting for 1.8\% of all sequences) were excluded. Mothur ver. 1.30.1 (Schloss et al., 2009) was used to calculate bacterial diversity indices (Shannon, Simpson, abundance-based coverage estimator (ACE), Chaol, and coverage). Heatmap was implemented by $\mathrm{R}$ packages heatmap (http://www.r-projet.org/) (Lin et al., 2014). R vegan package was used to estimate the weighted UniFrac metric and to perform principal coordinate analysis (PCoA) (Noyce et al., 2016). Redundancy analysis (RDA) was employed to explore the relationship between environmental factors and bacterial communities. One way analysis of variance (ANOVA) tests were performed to assess the statistically significant difference of diversity indices between samples. Differences were considered significant at $p<0.05$. Venn diagrams were drawn using online tool "Draw Venn Diagram" (http://bioinformatics.psb.ugent.be/ webtools/Venn) to analyze overlapped and unique OTUs during the treatment processes. One-way permutational analysis of variance (PERMANOVA) was performed using $R$ vegan package to assess the statistically significant effects of treatment processes on bacterial communities (Anderson and Walsh, 2013).

\section{Prediction of Functional Profiles}

For functional composition prediction, PICRUSt-compatible OTU tables were constructed using the closed-reference OTUpicking strategy (pick_closed__referfence_otus. py, uclust similarity cutoff at 0.97 , Greengene v13_8) in QIIME 1.8.0 (Langille et al., 2013). The resulting OTU table was uploaded into the PICRUSt 1.0.0 on the Galaxy server (http://huttenhower. sph.harvard.edu/galaxy/). The functional information were annotated according to the Kyoto Encyclopedia of Genes and Genomes (KEGG) database. The values of Nearest Sequenced Taxon Index (NSTI) for all the samples were between 0.10 and 0.24 , indicating relatively accurate predictions. The non-metric multidimensional scaling (NMDS) plot was made using $\mathrm{R}$ vegan package based on PICRUSt analysis.

\section{RESULTS AND DISCUSSION}

\section{Physicochemical Properties of Water}

The water quality parameters of the source and treated water at each sampling time are shown in Table 1. All the water quality parameters varied, but the treated water always met the water quality standard (GB5749-2006). The TOC removal rates during the treatment processes are shown in Figure 2A. Flocculation-sedimentation, sand filtration and BAC filtration were important processes for TOC removal and their TOC removal rates relatively stabilized at $10-15 \%, 20 \%$ and more than $20 \%$, respectively. The rates of turbidity and ammonia nitrogen removal in each treatment process were illustrated in Figure 2B. More than $90 \%$ of turbidity was removed by flocculation-sedimentation. The turbidity of all samples was below 1 NTU after flocculation-sedimentation. Sand filtration and BAC filtration subsequently removed approximately 60 and $20 \%$ of turbidity, respectively. All the treatment processes except for post-ozonation contributed to the removal of ammonia nitrogen. Post-ozonation increased the concentration of ammonia nitrogen by approximately $30 \%$, which may be due to the products of nitrogenous organic matter decomposition (LeLacheur and Glaze, 1996). Chlorine disinfection had the highest rate (47-66\%) of ammonia nitrogen removal because of the reaction of chlorine and ammonia nitrogen (Hayes-Larson and Mitch, 2010). The removal rates of all the parameters did not significantly differ among different seasonal samples $(p>0.05)$.

\section{Effects of Treatment Processes on Bacterial Communities}

The community richness and diversity indices at each treatment step during seasonal sampling are shown in Table 2. With a 97\% similarity cutoff, 22,522, 10,142, 12,345, and 17,132 OTUs were acquired in November, January, May and July, respectively. After post-ozonation, the Chaol and Shannon indices respectively 
TABLE 2 | Bacterial community richness and diversity indices at each treatment step and the four sampling times.

\begin{tabular}{|c|c|c|c|c|c|c|c|}
\hline \multicolumn{2}{|c|}{ Sample by type and date } & \multirow{2}{*}{$\begin{array}{c}\text { OTUs } \\
1486\end{array}$} & \multirow{2}{*}{$\begin{array}{c}\text { Coverage } \\
0.944\end{array}$} & \multirow{2}{*}{$\begin{array}{l}\text { ACE } \\
5800\end{array}$} & \multirow{2}{*}{$\begin{array}{c}\text { Chao1 } \\
3451\end{array}$} & \multirow{2}{*}{$\begin{array}{c}\text { Shannon } \\
4.90\end{array}$} & \multirow{2}{*}{$\frac{\text { Simpson }}{0.032}$} \\
\hline RW & Nov. & & & & & & \\
\hline & Jan. & 834 & 0.976 & 2517 & 1659 & 4.58 & 0.024 \\
\hline & May & 1480 & 0.963 & 3292 & 2502 & 5.04 & 0.027 \\
\hline & Jul. & 1147 & 0.971 & 2830 & 2078 & 4.53 & 0.042 \\
\hline \multirow[t]{4}{*}{ PROE } & Nov. & 1508 & 0.952 & 4697 & 3208 & 4.49 & 0.044 \\
\hline & Jan. & 840 & 0.976 & 2347 & 1674 & 4.55 & 0.026 \\
\hline & May & 1448 & 0.961 & 3594 & 2652 & 5.05 & 0.024 \\
\hline & Jul. & 1522 & 0.959 & 3802 & 2836 & 4.94 & 0.030 \\
\hline \multirow[t]{4}{*}{ SE } & Nov. & 2459 & 0.926 & 6093 & 4289 & 5.28 & 0.031 \\
\hline & Jan. & 586 & 0.983 & 1796 & 1264 & 3.98 & 0.041 \\
\hline & May & 608 & 0.983 & 1717 & 1285 & 3.62 & 0.074 \\
\hline & Jul. & 957 & 0.973 & 2950 & 1973 & 3.23 & 0.193 \\
\hline \multirow[t]{4}{*}{ SFE } & Nov. & 1643 & 0.951 & 4730 & 3133 & 4.59 & 0.038 \\
\hline & Jan. & 649 & 0.983 & 1782 & 1335 & 4.20 & 0.034 \\
\hline & May & 856 & 0.978 & 2134 & 1590 & 3.74 & 0.074 \\
\hline & Jul. & 1477 & 0.961 & 3732 & 2662 & 3.78 & 0.168 \\
\hline \multirow[t]{4}{*}{ PSOE } & Nov. & 2878 & 0.925 & 4738 & 4258 & 6.37 & 0.008 \\
\hline & Jan. & 766 & 0.981 & 1760 & 1428 & 4.58 & 0.030 \\
\hline & May & 1277 & 0.970 & 2558 & 2093 & 4.54 & 0.049 \\
\hline & Jul. & 2630 & 0.940 & 4146 & 3884 & 5.89 & 0.021 \\
\hline \multirow[t]{4}{*}{ BACE } & Nov. & 3402 & 0.910 & 6807 & 5231 & 6.91 & 0.003 \\
\hline & Jan. & 1527 & 0.964 & 3184 & 2469 & 5.62 & 0.010 \\
\hline & May & 1883 & 0.959 & 3677 & 2944 & 5.86 & 0.012 \\
\hline & Jul. & 2181 & 0.953 & 4088 & 3326 & 6.15 & 0.010 \\
\hline \multirow[t]{4}{*}{ DW } & Nov. & 3011 & 0.917 & 4733 & 4237 & 6.13 & 0.019 \\
\hline & Jan. & 964 & 0.979 & 1425 & 1300 & 4.15 & 0.053 \\
\hline & May & 1609 & 0.963 & 2558 & 2297 & 4.77 & 0.036 \\
\hline & Jul. & 2612 & 0.946 & 3751 & 3444 & 5.78 & 0.036 \\
\hline \multirow[t]{4}{*}{ USB } & Nov. & 1185 & 0.967 & 3406 & 2245 & 4.46 & 0.038 \\
\hline & Jan. & 939 & 0.976 & 2349 & 1741 & 4.49 & 0.035 \\
\hline & May & 655 & 0.986 & 1413 & 1047 & 4.10 & 0.045 \\
\hline & Jul. & 1065 & 0.977 & 2256 & 1804 & 5.01 & 0.023 \\
\hline \multirow[t]{4}{*}{ MSB } & Nov. & 990 & 0.974 & 2644 & 1914 & 4.36 & 0.048 \\
\hline & Jan. & 806 & 0.981 & 1826 & 1437 & 4.45 & 0.034 \\
\hline & May & 641 & 0.985 & 1574 & 1057 & 4.09 & 0.041 \\
\hline & Jul. & 954 & 0.978 & 2357 & 1787 & 4.76 & 0.032 \\
\hline \multirow[t]{4}{*}{ UBACB } & Nov. & 2167 & 0.946 & 4675 & 3375 & 6.04 & 0.011 \\
\hline & Jan. & 1033 & 0.978 & 1982 & 1724 & 4.59 & 0.065 \\
\hline & May & 974 & 0.981 & 1706 & 1427 & 4.82 & 0.037 \\
\hline & Jul. & 1144 & 0.975 & 2321 & 1837 & 4.88 & 0.025 \\
\hline \multirow[t]{4}{*}{ MBACB } & Nov. & 1793 & 0.956 & 4127 & 3011 & 5.75 & 0.014 \\
\hline & Jan. & 1198 & 0.977 & 2075 & 1693 & 5.00 & 0.049 \\
\hline & May & 914 & 0.981 & 1697 & 1520 & 4.44 & 0.064 \\
\hline & Jul. & 1443 & 0.970 & 2779 & 2233 & 5.57 & 0.013 \\
\hline
\end{tabular}

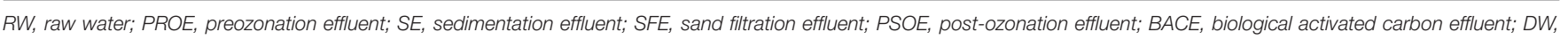
disinfected water; USB, upper sand biofilm; MSB, middle sand biofilm; UBACB, upper biological activated carbon biofilm; MBACB, middle biological activated carbon biofilm. 


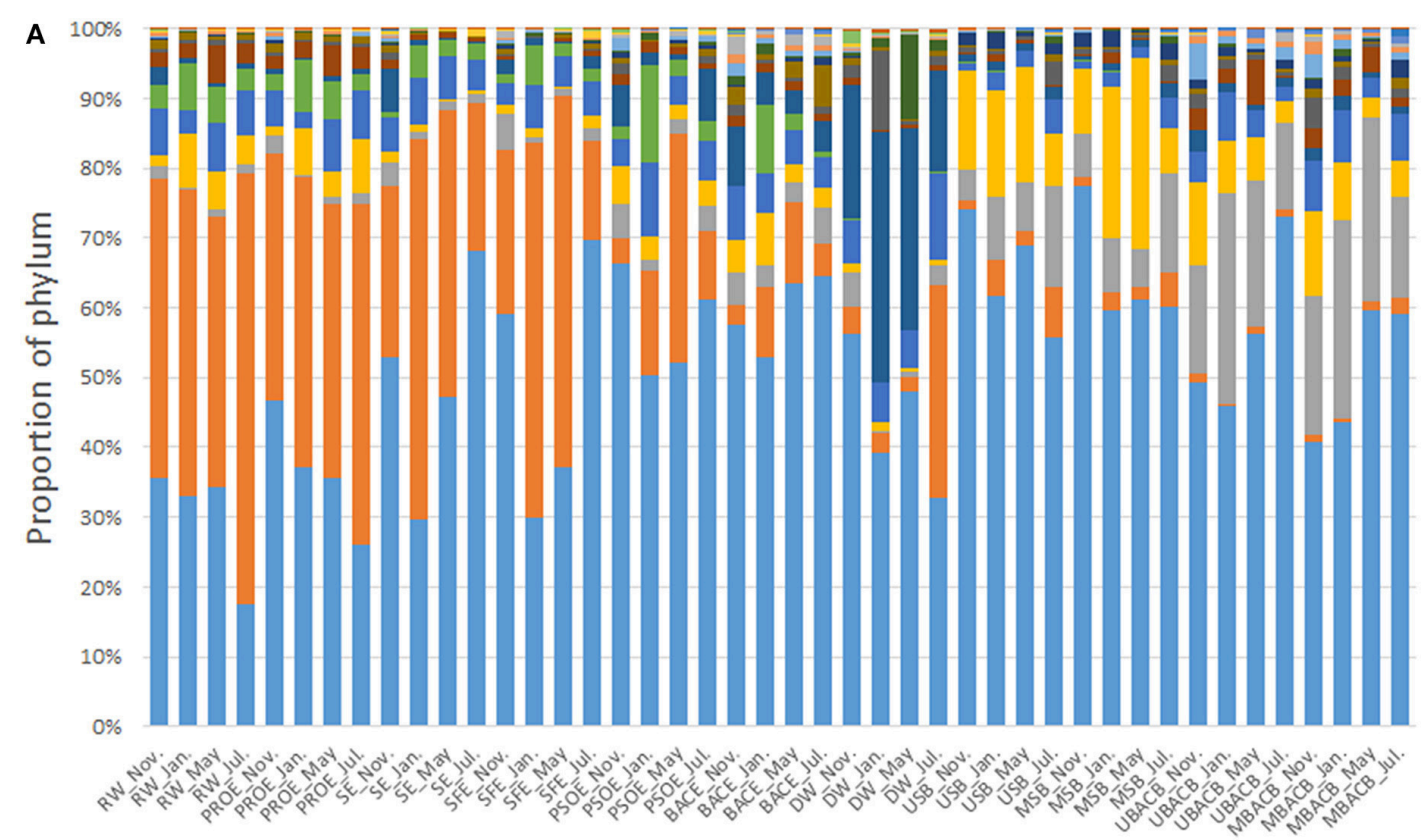

\begin{tabular}{|c|c|c|c|}
\hline - Proteobacteria & E Actinobacteria & Acidobacteria & wanctomycetes \\
\hline Bacter oidetes & घCyanobacteria & a Firmicutes & a Verrucomicrobia \\
\hline - Chibroflexi & anclassified & nitrospirae & Deinococcus-Thermus \\
\hline a Chlamydiae & - CandidatusSac & a Parcubacteria & n Gemmatimonadetes \\
\hline armatimonadetes & Wpirochaetes & - Latesc bacter ía & - Euryarchaeota \\
\hline
\end{tabular}

B

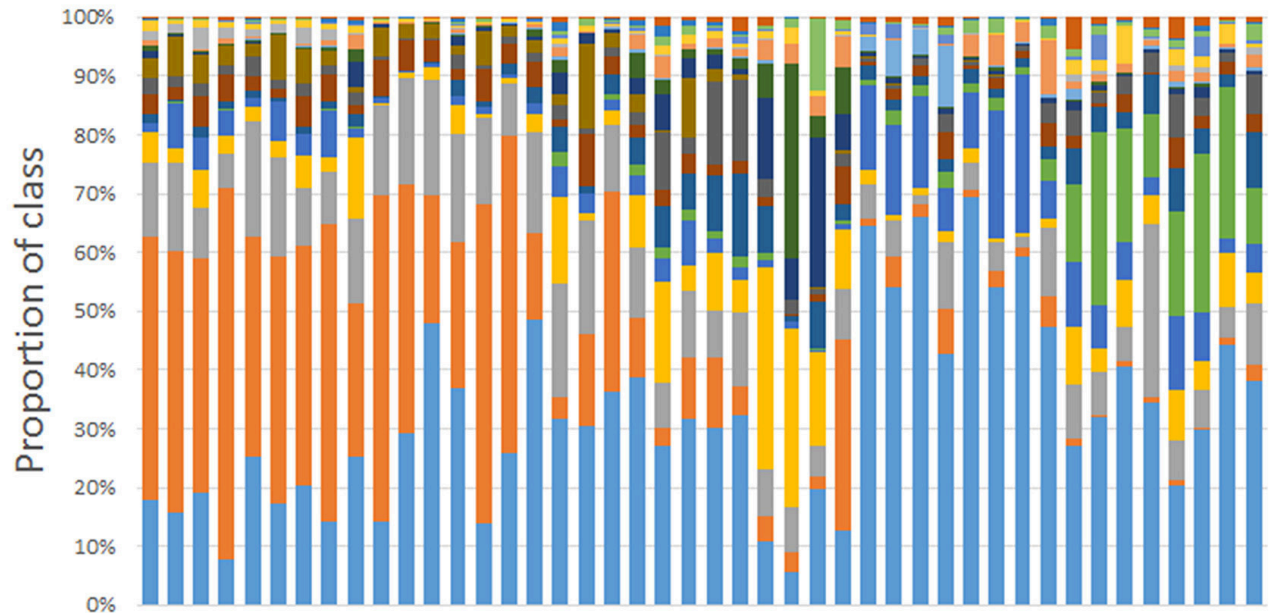

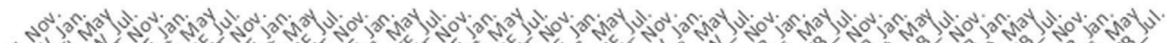
का

\begin{tabular}{|c|c|c|c|c|}
\hline Alphapr oteobacter ia & actinobacteria & (netaproteobacteria & \multicolumn{2}{|c|}{ Wammaproteobacteria a Planctomycetia } \\
\hline Acidobacteria_Gp4 & E Deltaproteobacteria & - Sphingobacteriia & घunclassified & nCyanobacteria \\
\hline - Bacilli & a Clostridia & Acidobacteria_Gp3 & Bacter oidia & @ Spartobacteria \\
\hline Flavobacteriia & Nitrospira & Deinococci & aChlamydila & acidobacteria_Gp6 \\
\hline
\end{tabular}

FIGURE 3 | Relative abundance of bacterial phyla (A) and classes (B) at each treatment step. The top 20 most abundant phyla or classes are shown. The abbreviations are the same as used in Table 2. 

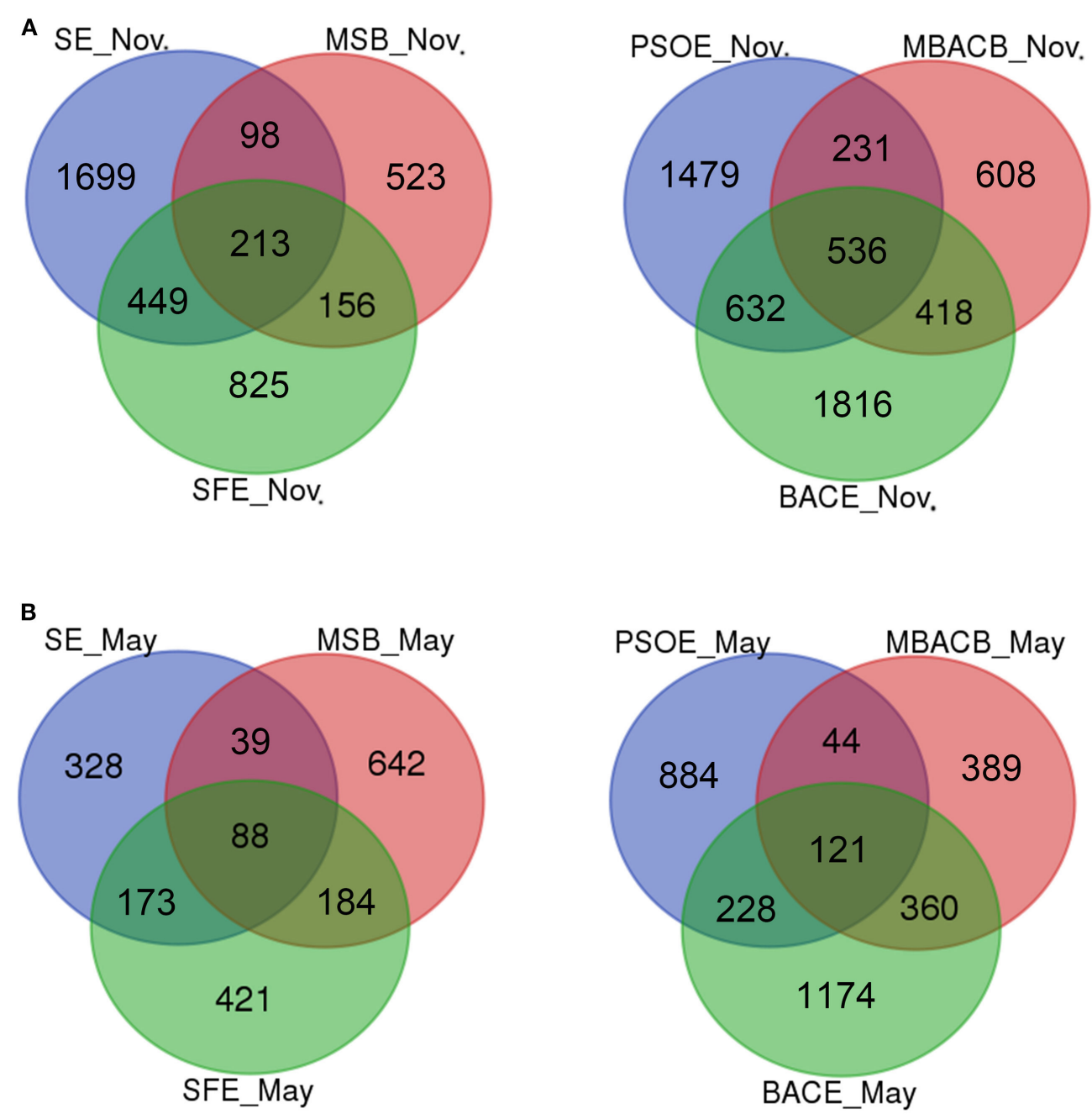

FIGURE 4 | Venn diagrams showing the number of shared OTUs between filter biofilms and their corresponding influents and effluents in November (A) and May (B) The abbreviations are the same as used in Table 2.

increased from $1,335-3,133$ to $1,428-4,258$ and from $3.74-4.59$ to 4.54-6.37 $(p>0.05)$. Chlorine disinfection reduced the richness and diversity indices (Chaol and Shannon indices) from 2,4695231 to $1,300-4,237$ and from $5.62-6.91$ to $4.15-6.13(p>0.05)$, respectively. The influence of treatment processes on the richness and diversity of bacterial community was not significant. The richness and diversity of the bacterial community varied in each process step with sampling time. However, associations between these variables were not found.

The effects of the major treatment process steps on the bacterial communities were investigated using Venn diagrams (Figure S1). In total, 54-193 OTUs were universally present from raw water to disinfected water at different sampling times. The percentages of the total number of OTUs that are common during the treatment process were 1.5, 1.1, 1.0, and $1.1 \%$ in November, January, May and July, respectively, indicating that the common OTUs accounted for a very small portion of the OTUs detected. Samples from each major-step, namely sand filtration, post-ozonation, BAC filtration and chlorine disinfection, contained $22-67 \%$ unique OTUs (Figure S1). The percentage of unique OTUs was largest in the effluent of the BAC filter and disinfected water (40-53\% and 36-67\%, respectively), indicating that BAC filtration and disinfection had power to shape the microbiome. The effluent from sand filtration had the lowest proportion of unique OTUs (22-27\%), which implied that sand filtration exerted a weaker influence on the bacterial community than the other major process steps.

PERMANOVA revealed that no significant differences existed between the bacterial community structures in two successive sampling sites, namely raw water and preozonation effluent ( $F=0.32, P=0.836)$, preozonation and sedimentation effluents ( $F=2.03, P=0.069)$, sedimentation and sand filtration effluents $(F=0.44, P=0.791)$, sand filtration and post-ozonation effluents $(F=1.16, P=0.296)$, and post-ozonation and BAC filtration effluents $(F=1.26, P=0.163)$. Similarly, the differences of bacterial community structures between preozonation and sand filtration and between sedimentation and post-ozonation were not significant $(P>0.05)$. Except for the mentioned above, 


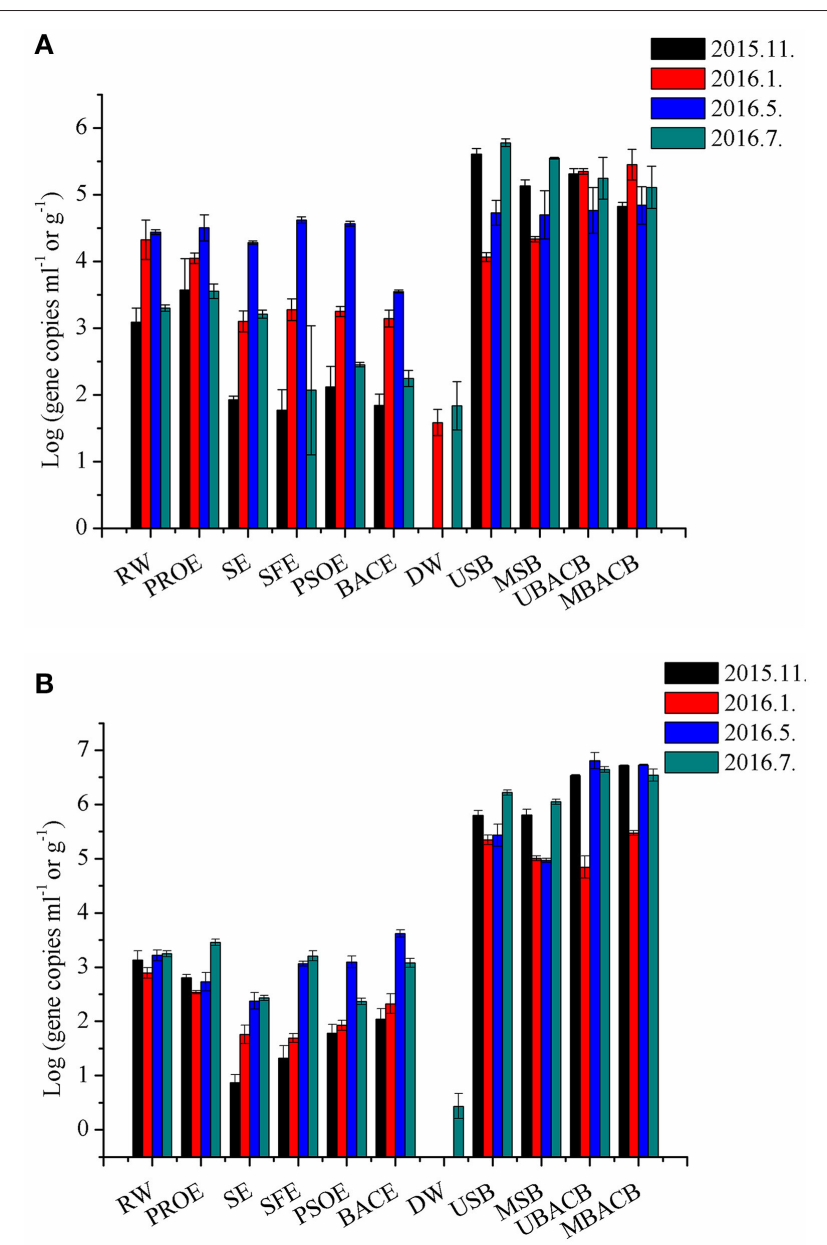

FIGURE 5 | QPCR results for Mycobacterium spp. (A) and Legionella spp. (B) at each treatment step during seasonal sampling. The abbreviations of the samples are the same as used in Table 2

the differences between the bacterial community structures of random two samples were significant $(P<0.05)$. For sequential water samples, only BAC effluent and disinfected water exhibited a significant difference $(F=1.73, P=0.027)$, indicating that all the individual treatment processes except disinfection had no significant effects on the bacterial community. Conversely, the bacterial community was shaped by a combination of multistep processes.

\section{Variations in Bacterial Community Composition during Treatment Processes}

The top 20 most abundant phyla of bacterial community detected at the 11 sampling locations and four sampling times is shown in Figure 3A. The bacterial community composition in raw water, preozonation effluent, sedimentation effluent, sand filtration effluent and biofilm samples remained relatively stable despite the variations in proportions of Proteobacteria and Actinobacteria during seasonal sampling. However, the bacterial community composition in post-ozonation, BAC filtration effluent and

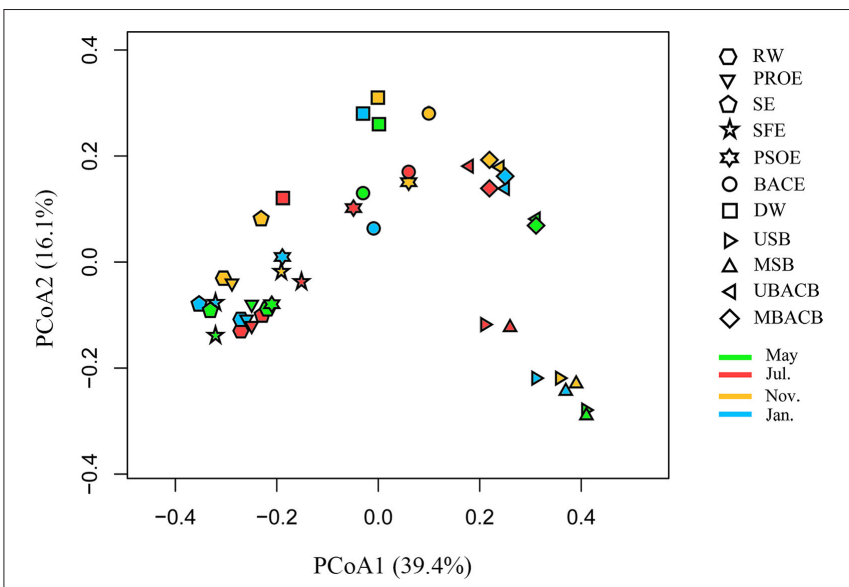

FIGURE 6 | Principal coordinates analysis (PCOA) of the samples using weighted UniFrac metrics. The abbreviations of the samples are the same as used in Table 2.

disinfected water samples varied at different sampling times. The predominant phyla, other than Proteobacteria (38.54$64.96 \%$ ), in post-ozonation samples differed in different seasonal samples. They were Firmicutes (5.73\%), Planctomycetes $(5.29 \%)$ and Acidobacteria (4.7\%) in November, Proteobacteria (38.54\%), Actinobacteria (11.46\%) and Cyanobacteria (34.14\%) in January, Actinobacteria (32.26\%) in May and Actinobacteria (9.64\%), Firmicutes (7.44\%) and Bacteroidetes (5.73\%) in July. The predominant bacteria in BAC filtration effluent similarly varied and were Firmicutes (8.38\%) and Bacteroidetes (7.66\%) in November; Cyanobacteria (18.65\%) and Actinobacteria (9.08\%) in January; Actinobacteria (11.47\%) and Bacteroidetes (4.87\%) in May and Acidobacteria (5.13\%) and Actinobacteria (4.64\%) in July, in addition to the most predominant phylum overall (Proteobacteria, 47.64-64.01\%). Compared with the groups in post-ozonation and BAC filtration effluents, the predominant bacterial groups in disinfected water were relatively consistent (Proteobacteria at 32.19-55.3\%, Firmicutes at 14.07-34.56\%), except for a high level of Deinococcus-Thermus (11.71\%) in May and Actinobacteria (30.14\%) in July.

Proteobacteria, Actinobacteria, and Firmicutes dominated in different samples. Actinobacteria and Proteobacteria dominated in raw water, constituting $37.7-61.4 \%$ and $17.3-34.9 \%$ of the total sequences, respectively. The proportion of Actinobacteria gradually decreased along the sequential steps of preozonation, flocculation, sedimentation and sand filtration, while the proportion of Proteobacteria correspondingly increased. The abundance of Actinobacteria dramatically decreased from 14.3$52.7 \%$ to $3.4-32.3 \%$ after post-ozonation, resulting in the absolute predominance of Proteobacteria. Unlike Actinobacteria, Proteobacteria dominated in all the samples, including those of water and biofilms. Chlorine disinfection decreased the proportion of Proteobacteria from 47.6-64.0\% to 32.19-55.3\%. In contrast, the proportion of Firmicutes increased from $3.4-8.4 \%$ to $14.1-34.6 \%$ after disinfection.

The top 20 most abundant classes of bacterial community at all the sampling locations is presented in Figure 3B. 


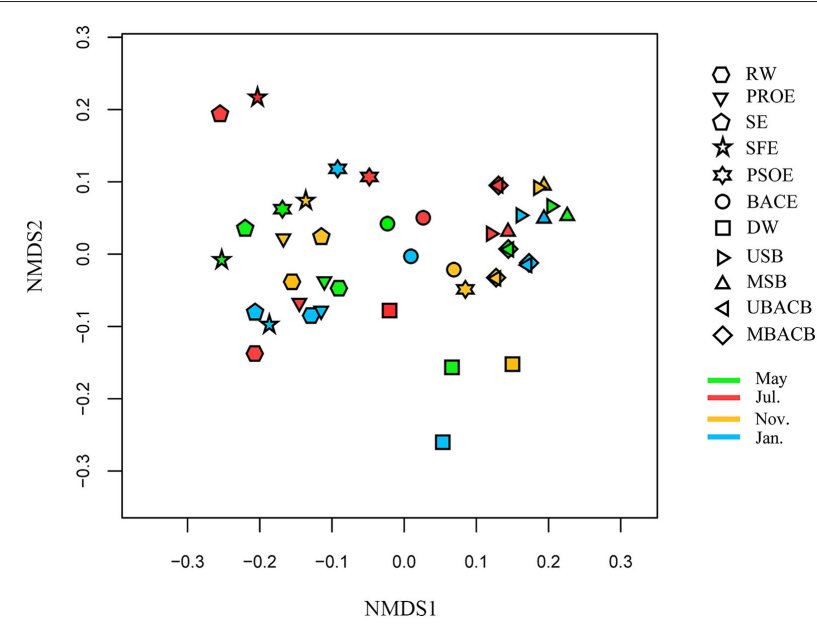

FIGURE 7 | NMDS analysis based on predictive functional genes. The abbreviations of the samples are the same as used in Table 2.

Similar to the variations in phyla, the class-level bacterial composition of post-ozonation, BAC filtration effluent and disinfected water differed with seasons. Proteobacteria is comprised of five subclasses, Alpha-, Beta-, Gamma-, Delta-, and Epsilonproteobacteria. Alphaproteobacteria was the most prevailing subclass within Proteobacteria in all the samples (accounting for approximately 50\% of Proteobacteria), followed by Betaproteobacteria (approximately 30\%), except in disinfected water. In disinfected water, the proportion of Gammaproteobacteria ( $30 \%$ ) within Proteobacteria approached that of Alphaproteobacteria $(\sim 35 \%)$ in May and July and was six to seven times than that of Alphaproteobacteria $(\sim 15 \%)$ in November and January. In addition to Gammaproteobacteria, Bacilli and Clostridia dominated in disinfected water. They both belong to Firmicutes and accounted for similar proportions (5.75-24.15\% and $5.32-28.18 \%$, respectively) of the bacterial classes in disinfected water.

Proteobacteria, the dominant phylum in all the samples, is the most common bacteria in freshwater lakes. Of the five subclasses of Proteobacteria, Alphaproteobacteria predominated because of its competitive advantages under conditions of low nutrient availability and its capability to degrade complex organic compounds (Eiler et al., 2003; Hutalle-Schmelzer et al., 2010). By contrast, Betaproteobacteria prefer to proliferate in nutrientrich environments (Newton et al., 2011), which leads to its weak competitiveness in oligotrophic environments. Although Gammaproteobacteria was only abundant in disinfected water, it should receive more attention because of its increase after chlorine disinfection. The dominance of Gammaproteobacteria in disinfected water was possibly due to its great resistance to chlorine (Mi et al., 2015; Belila et al., 2016; Pang et al., 2016; Stanish et al., 2016).

Actinobacteria are commonly found and often numerically important in a variety of freshwater habitats (Glöckner et al., 2000; Zwart et al., 2002). Actinobacteria accounted for the largest proportion of bacterial phyla in raw water.
However, they decreased during the treatment processes, implying their vulnerability to treatment (Servais et al., 1994). In contrast, Bacteroidetes maintained at a constant level in all the samples, reflecting its resistance to treatment processes. The proportion of Firmicutes increased after chlorine disinfection, which may be attributed to the greater resistance of Gram-positive bacteria (Firmicutes) than Gramnegative bacteria (Proteobacteria) to chlorine (Mir et al., 1997).

\section{Characteristics of Bacterial Communities from Water and Different Filters}

Species richness indices did not differ in water and biofilm samples (Table 2). The bacterial diversity estimators of BAC biofilms were higher than that of sand biofilms during the sampling time, with a larger number of OTUs (914-2167) and higher values of Chao1 (1427-3375) and Shannon indices (4.446.04) in BAC biofilms than sand biofilms [641-1185 OTUs, Chaol indices (1047-2245) and Shannon indices (4.09-5.01)] (Table 2). However, the differences were not significant $(p>$ 0.05). Both sand and BAC biofilms shared more OTUs with their corresponding effluents (28.6-56.3\% and 25.6-59.4\% of biofilm samples, respectively) than with their respective influents (13.4$32 \%$ and $16.8-47.3 \%$ of biofilm samples, respectively) (data of November and May shown in Figure 4, and data of January and July shown in Figure S2), which implied that filter media selected for surface-associated bacteria and affected the subsequent flow, despite being seeded by the influent (Dang and Lovell, 2016).

Bacterial community structures of biofilm samples were significantly different from those of water samples (PERMANOVA, $P<0.05$ ). The bacterial community composition was similar between the upper and middle parts of each type of filter (sand filter, PERMANOVA, $F=0.20, P=$ 0.823; BAC filter, PERMANOVA, $F=0.37, P=0.877$ ). However, there was a significant difference in bacterial communities between sand and BAC biofilms (upper part, PERMANOVA, $F$ $=5.37, P=0.029$; middle part, PERMANOVA, $F=5.30, P=$ 0.024). The Actinobacteria population, which were dominant in water, became the minor group in biofilms (less than $8 \%$ ) (Figure 3A). Similarly, the abundance of Cyanobacteria was higher in water $(1-15 \%)$ than biofilms $(<0.1-2 \%)$. Their low abundance on filter materials indicated that they did not tend to form biofilms (Parfenova et al., 2013). In contrast, Acidobacteria and Planctomycetes, which were present in low proportions in water (no more than $7 \%$ each), were relatively abundant in biofilms. Acidobacteria accounted for $4.4-14.4 \%$ and $12.2-$ $30.0 \%$ of the phyla in sand and BAC biofilms, respectively, while the proportions of Planctomycetes were $6.4-27.3 \%$ and 2.8-12.1\%. Within Acidobacteria, Acidobacteria_Gp4 (59.895.8\% of Acidobacteria) predominated in BAC biofilms, while Acidobacteria_Gp3 (54.2-69.8\% of Acidobacteria) dominated in sand biofilms (Figure 3B). The predominance of Acidobacteria and Planctomycetes in biofilms may be due to their physiological and genetic traits related to surface living (Dang and Lovell, 2016), and they are widely distributed in drinking water biofilms (Schmeisser et al., 2003; Martiny et al., 2005; Qin et al., 2007). In 


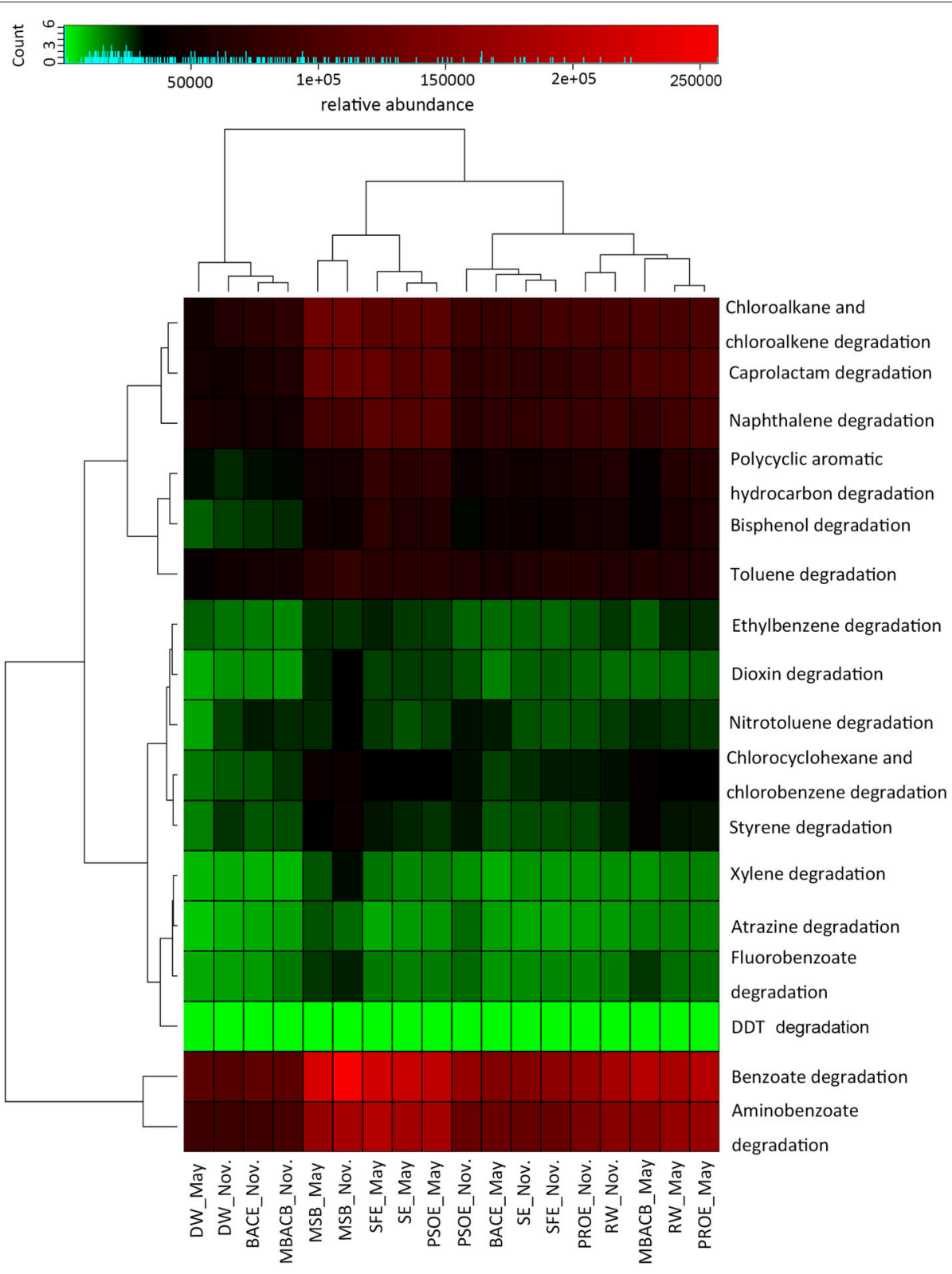

FIGURE 8 | Heatmap of functional genes relating to pollutant degradation predicted using PICRUSt along the treatment processes in November and May. The relative abundance of each functional gene is indicated by color intensity with the legend at the top. The upper and left panels show the hierarchical clustering. The abbreviations of the samples are the same as used in Table 2. DDT is short for 2,2-bis(4-chlorophenyl)-1,1,1-trichloroethane.

contrast, the abundance of Bacteroidetes differed little between planktonic and sessile forms, accounting for $2.3-7.3 \%$.

\section{Quantitative Analysis of Mycobacterium spp. and Legionella spp.}

The genus Mycobacterium, well known for its resistance to disinfectants (Simoes and Simoes, 2013), was present in a higher proportion $(7.24 \%)$ in post-ozonation in May and disinfected water $(8.30 \%)$ in January (Figure S3A). However, the proportion that Mycobacterium spp. accounted for in disinfected water varied with seasonal changes significantly $(p<0.05)$. Both
Mycobacterium spp. and Legionella spp. had more gene copies in biofilms than water (Figure 5). However, Mycobacterium spp. accounted for quite a small proportion in biofilms, compared to water (Figure S3A). In contrast, Legionella spp. presented the accumulation on BAC filters (Figure S3B), resulting in their increase in BAC effluents, which posed a potential threat to consumers. Fortunately, chlorine disinfection effectively eliminated Legionella spp. $(p<0.05)$.

Ozone is reported to be a more powerful disinfectant than free chlorine and chlorine dioxide due to its highest oxidation potential of $2.07 \mathrm{~V}$ (Taylor et al., 2000; Cho et al., 2010). 


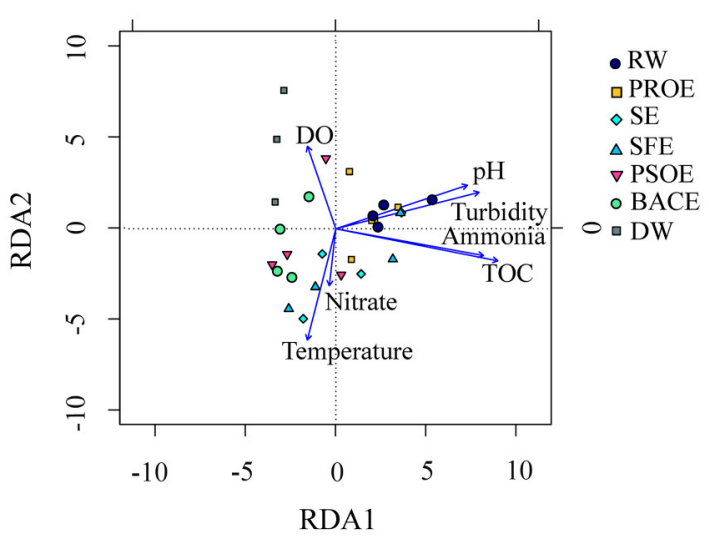

FIGURE 9 | Redundancy analysis (RDA) of main bacterial phyla and environmental parameters. The abbreviations of the samples are the same as used in Table 2

However, researchers found that double-layered gram-positives such as Mycobacterium survived and became predominant after ozonation (Lee and Deininger, 2000). In our study, gene copies and proportions of Mycobacterium and Legionella increased after ozonation (Figure 5 and Figure S3). Therefore, it is necessary to quantify potential pathogens using qPCR, especially in disinfected water. In addition, inactivation methods that are more effective should be used to guarantee drinking water safety.

\section{Temporal and Spatial Dynamics of Microbial Communities}

The dynamics of community structures at all the sampling locations and time points are illustrated in Figure 6. Principal Axis 1 and Principal Axis 2 for PCoA represent 39.4 and 16.1\% of the variation among the samples, respectively. Biofilm and water samples occupied divergent positions. The water samples clustered before post-ozonation, then distinctly separated during seasonal sampling after post-ozonation. Seasonal post-ozonation samples exhibited a dispersive distribution. The results from PERMANOVA revealed that the samples with no significant difference from two sampling sites included raw water and preozonation effluent, preozonation and sedimentation effluents, sedimentation and sand filtration effluents, sand filtration and post-ozonation effluents, post-ozonation and BAC effluents and BAC effluent and disinfected water $(P>0.05)$. All these samples with no significant difference had a feature of at least one sample from each sampling site clustering closely (Figure 6). According to PERMANOVA, disinfection was the only individual treatment step which significantly influenced bacterial community $(P<$ 0.05) (Kim et al., 2013). Thus, the dynamics of the disinfected water samples were different from those of the other water samples (Figure 6). Alternatively, BAC biofilms separated from sand biofilms, but they each clustered despite different sampling depths and time. These biofilm dynamics revealed that biofilm bacterial communities were uniform from the surface to middle part of each filter, with high stability between different sampling times.
The bacterial community structure at each treatment step (except post-ozonation and BAC filtration effluents) was relatively stable during seasonal sampling. A reasonable explanation was that the community structure was governed by broader environmental conditions than temperature alone (Kim et al., 2013; Zwirglmaier et al., 2015). The dynamics of the microbial communities were mainly affected by the treatment processes rather than seasonal changes. A previous study also found that activated sludge communities were shaped by treatment processes (Lee et al., 2015). The susceptibility of the bacterial community in post-ozonation effluent to seasonal changes may be due to the great impacts of temperature on the solubility and decay of ozone (Gardoni et al., 2012). Compared with the water quality changes from the high ozone dosage in post-ozonation $(1 \mathrm{mg} / \mathrm{L})$, preozonation (with the lower dosage of $0.5 \mathrm{mg} / \mathrm{L}$ ) changed water quality little, leading to a bacterial community in preozonation effluent that is more stable with regard to seasonal changes. The clustering of samples before post-ozonation illustrated the negligible effects of preozonation, flocculation, sedimentation and sand filtration on shifting the microbiome (Li et al., 2017; Xu et al., 2017). The samples before BAC filtration separated from the samples after BAC filtration, which was consistent with the previous find that filtration shaped the bacterial community in the corresponding effluent (Lautenschlager et al., 2014).

\section{Variations of Pollutant Degradation Functions during the Treatment Processes}

The results of the NMDS analysis of the samples based on predictive functional genes is illustrated in Figure 7. The water samples dispersed without obvious clustering. These functional profiles displayed no seasonal associations. The functions of biofilm samples were more stable than those of water samples In addition, the clustering of sand and BAC biofilms implied their similarity in function despite their discrepancy in community composition, which may be attributed to functional redundancy within communities (Allison and Martiny, 2008).

The KEGG pathway-related functional profiles that were predicted using PICRUSt can be classified into several functional groups, including metabolism, genetic information processing, cellular processes and environmental information processing. Some functions relating to pollutant degradation, such as atrazine degradation, bisphenol degradation and naphthalene degradation, were identified in the xenobiotics degradation and metabolism profiles of the samples. Variations of pollutant degradation functions along the treatment processes in November and May are illustrated in Figure 8. The numbers of sequences assigned to pollutant degradation were the lowest and highest in November and May, respectively. The ability to degrade each type of pollutants differed in abundance. High percentages of sequences were assigned to aminobenzoate, benzoate, caprolactam, chloroalkane, and naphthalene degradation, while low percentage of sequences were assigned to 2,2-bis(4-chlorophenyl)-1,1,1-trichloroethane (DDT) degradation. The abundance of genes involved in pollutant biodegradation generally showed decreased during the 
TABLE 3 | Correlations between the water quality parameters and the relative abundance of predominant bacterial phyla and proteobacterial classes.

\begin{tabular}{|c|c|c|c|c|c|c|}
\hline Classification & Temperature & $\mathrm{pH}$ & Turbidity & Ammonia nitrogen & DO & TOC \\
\hline Proteobacteria & 0.30 & $-0.51^{b}$ & $-0.57^{b}$ & $-0.44^{a}$ & -0.06 & $-0.48^{a}$ \\
\hline Alphaproteobacteria & $0.40^{a}$ & -0.26 & $-0.38^{a}$ & -0.18 & -0.22 & -0.23 \\
\hline Gammaproteobacteria & -0.05 & $-0.49^{b}$ & -0.24 & $-0.47^{\mathrm{a}}$ & 0.13 & $-0.41^{\mathrm{a}}$ \\
\hline Deltaproteobacteria & 0.28 & $-0.52^{b}$ & -0.35 & $-0.42^{a}$ & -0.16 & $-0.58^{b}$ \\
\hline Actinobacteria & -0.01 & $0.44^{\mathrm{a}}$ & $0.54^{b}$ & $0.59^{b}$ & $-0.22^{b}$ & $0.68^{C}$ \\
\hline Cyanobacteria & $-0.59^{b}$ & $0.72^{\mathrm{C}}$ & 0.06 & 0.22 & $0.55^{b}$ & 0.06 \\
\hline Firmicutes & -0.09 & $-0.48^{a}$ & -0.32 & $-0.58^{b}$ & 0.11 & $-0.52^{b}$ \\
\hline Planctomycetes & -0.14 & $0.49^{b}$ & $0.51^{\mathrm{b}}$ & $0.47^{\mathrm{a}}$ & 0.18 & 0.32 \\
\hline Acidobacteria & 0.26 & $-0.45^{\mathrm{a}}$ & -0.37 & -0.31 & 0.00 & -0.31 \\
\hline Verrucomicrobia & 0.16 & 0.35 & $0.93^{d}$ & $0.70^{c}$ & -0.25 & $0.69^{c}$ \\
\hline Nitrospirae & $0.44^{\mathrm{a}}$ & $-0.40^{\mathrm{a}}$ & -0.25 & -0.19 & -0.18 & -0.28 \\
\hline Gemmatimonadetes & $0.59^{b}$ & $-0.49^{b}$ & -0.21 & -0.28 & $-0.40^{\mathrm{a}}$ & -0.16 \\
\hline Euryarchaeota & -0.03 & $-0.50^{b}$ & -0.28 & $-0.53^{b}$ & 0.06 & $-0.48^{a}$ \\
\hline
\end{tabular}

a Significance $<0.05,{ }^{b}$ Significance $<0.01,{ }^{c}$ Significance $<0.0001,{ }^{d}$ Significance $<1 E-10$.

treatment processes. These functional profiles, except for DDT degradation, were most abundance on the sand filter. These findings revealed that microbes in the treatment processes were possibly involved in the degradation of a variety of organic pollutants and that the role of sand filtration in pollutant degradation may be underestimated. A previous study found that toxic chemicals increased abundance of microbial metabolic enzymes and pathways (Lu et al., 2017). The correlation between pollutant degradation functions and the concentration of the corresponding pollutants needs further research.

\section{Relationships between Bacterial Communities and Water Quality Parameters}

RDA was used to analyze the relationships between environmental parameters and bacterial community structures (Figure 9). RDA showed that turbidity, ammonia nitrogen and TOC exerted significant effects on community profiles $(p<0.01)$. Ammonia nitrogen and TOC were related to nutrition conditions (Zhang et al., 2009; Liao et al., 2013). Turbidity adjusted the proportions of particle-associated and free-living microbial communities (Dang and Lovell, 2016). The bacterial community structures in raw water and preozonation effluent samples positively correlated with $\mathrm{pH}$, turbidity, ammonia nitrogen and TOC with seasonal changes. The correlation strength of preozonation effluent particularly varied during seasonal sampling. The bacterial community in disinfected water positively correlated with DO.

Table 3 shows that the relative abundances of bacterial phyla and proteobacterial classes were correlated to water quality parameters. Higher temperatures were more favorable for Alphaproteobacteria, Nitrospirae and Gemmatimonadetes $(p<0.05$ or 0.01$)$ but more detrimental for Cyanobacteria $(p<0.01)$. The relative abundances of Actinobacteria, Cyanobacteria, and Planctomycetes positively correlated with $\mathrm{pH}$ values $(p<0.05)$, whereas those of Gammaproteobacteria, Deltaproteobacteria, Firmicutes, Acidobacteria, Nitrospirae,
Gemmatimonadetes, and Euryarchaeota negatively correlated ( $p$ $<0.05)$. Actinobacteria, Planctomycetes and Verrucomicrobia were powerful competitors in highly turbid water $(p<0.05)$, but Alphaproteobacteria was not $(p<0.05)$. Actinobacteria, Planctomycetes, and Verrucomicrobia positively correlated with ammonia nitrogen $(p<0.05)$. Conversely, Firmicutes, Gammaproteobacteria, Deltaproteobacteria, and Euryarchaeota negatively correlated with ammonia nitrogen $(p<0.05)$. High DO levels facilitated Cyanobacteria growth $(p<0.01)$, but inhibited Actinobacteria and Gemmatimonadetes. Actinobacteria and Verrucomicrobia were present in higher relative abundances in high-TOC environments $(p<0.01)$, whereas Firmicutes, Euryarchaeota, Gammaproteobacteria, and Deltaproteobacteria were more competitive in low-TOC environments $(p<0.05)$.

Alphaproteobacteria were relatively more abundant at high temperatures and low turbidity. Higher TOC and turbidity in raw water favored Actinobacteria (Glöckner et al., 2000; Wu et al., 2007), resulting in a larger number of Actinobacteria than Alphaproteobacteria. The decrease in TOC and turbidity during treatment decreased the Actinobacteria population. Similarly, Verrucomicrobia was relatively abundant in raw water and BAC filter, where the TOC concentrations were higher. By contrast, Firmicutes, Euryarchaeota, Gammaproteobacteria, and Deltaproteobacteria adapted to low-TOC environments, becoming highly abundant in treated water. In addition, low temperatures promoted the growth of Cyanobacteria, which is inconsistent with the previous reports of lake warming stimulating the growth of Cyanobacteria (Thomas and Litchman, 2016). The discrepancy may result from variations in the optimal growth temperatures of different Cyanobacteria (Lurling et al., 2013).

\section{CONCLUSIONS}

The drinking water treatment processes harbored a high diversity of bacteria. Proteobacteria, Actinobacteria, Acidobacteria, Planctomycetes, and Firmicutes were dominant bacterial phyla. 
Disinfection significantly influenced bacterial community structures, while other treatment processes synergized with their sequential processes to influence communities. The bacterial community composition in post-ozonation effluent, BAC effluent and disinfected water varied with seasonal changes. Bacterial communities in water and biofilms differed, and the latter mainly depended on filter materials. In contrast, biofilms on different filters have similar functional composition and similarly high stability. Although the water quality parameters of source water varied greatly in different seasons, the quality of the treated water remained relatively stable. Sand and BAC filtration effectively removed dissolved organic matters. PICRUSt analysis showed that functional genes related to degradation of some pollutants were widely distributed throughout the treatment processes, especially on sand and BAC filters. The two genera, Mycobacterium and Legionella, were quantified in the treatment processes. Chlorine was effective in removing most bacteria including some potential pathogens with the exception of Mycobacterium. Bacterial composition was determined by the interaction of all the water quality parameters, among which turbidity, ammonia nitrogen and TOC were the most important factors. This study was a comprehensive investigation into variations in microbial communities in a full-scale drinking water treatment plant during four representative months. Overall, bacteria in the treatment processes constituted a relatively stable bacterial community structure that contributed

\section{REFERENCES}

Allison, S. D., and Martiny, J. B. (2008). Resistance, resilience, and redundancy in microbial communities. Proc. Natl. Acad. Sci. U.S.A. 105(Suppl. 1), 11512-11519. doi: 10.1073/pnas.0801925105

Anderson, M. J., and Walsh, D. C. I. (2013). PERMANOVA, ANOSIM, and the Mantel test in the face of heterogeneous dispersions: what null hypothesis are you testing? Ecol. Monogr. 83, 557-574. doi: 10.1890/12-2010.1

APHA (2011). Standard Methods for the Examination of Water and Wastewater. Washington, DC: American Public Health Association.

Belila, A., El-Chakhtoura, J., Otaibi, N., Muyzer, G., Gonzalez-Gil, G., Saikaly, P. E., et al. (2016). Bacterial community structure and variation in a fullscale seawater desalination plant for drinking water production. Water Res. 94, 62-72. doi: 10.1016/j.watres.2016.02.039

Berjeaud, J. M., Chevalier, S., Schlusselhuber, M., Portier, E., Loiseau, C., Aucher, W., et al. (2016). Legionella pneumophila: the paradox of a highly sensitive opportunistic waterborne pathogen able to persist in the environment. Front. Microbiol. 7:486. doi: 10.3389/fmicb.2016.00486.

Brinkman, N. E., Haugland, R. A., Wymer, L. J., Byappanahalli, M., Whitman, R. L., and Vesper, S. J. (2003). Evaluation of a rapid, quantitative real-time PCR method for enumeration of pathogenic Candida cells in water. Appl. Environ. Microbiol. 69, 1775-1782. doi: 10.1128/AEM.69.3.1775-1782.2003

Camper, A. K., LeChevallier, M., Broadaway, S., and McFeters, G. (1986). Bacteria associated with granular activated carbon particles in drinking water. Appl. Environ. Microbiol. 52, 434-438.

Caporaso, J. G., Kuczynski, J., Stombaugh, J., Bittinger, K., Bushman, F. D., Costello, E. K., et al. (2010). QIIME allows analysis of highthroughput community sequencing data. Nat. Methods 7, 335-336. doi: 10.1038/nmeth.f.303

Chen, C., Khaleel, S. S., Huang, H., and Wu, C. H. (2014). Software for preprocessing Illumina next-generation sequencing short read sequences. Source Code Biol. Med. 9:8. doi: 10.1186/1751-0473-9-8 to water purification. However, potential pathogens, especially those resistant to disinfectants, posed a threat to public's health.

\section{AUTHOR CONTRIBUTIONS}

SY and LL conceived and supervised the study. QL and GL designed the experiments. QL, ZG, and YY performed the experiments. QL, ZL, and GL analyzed the data. QL wrote the paper. LR, QX, and ML revised the paper.

\section{FUNDING}

This work was funded by the National Major Project of the Science \& Technology Ministry of China (no. 2012ZX07403001).

\section{ACKNOWLEDGMENTS}

We would like to thank Huayan Company for helping sampling.

\section{SUPPLEMENTARY MATERIAL}

The Supplementary Material for this article can be found online at: https://www.frontiersin.org/articles/10.3389/fmicb. 2017.02465/full\#supplementary-material

Cho, M., Kim, J., Kim, J. Y., Yoon, J., and Kim, J. H. (2010). Mechanisms of Escherichia coli inactivation by several disinfectants. Water Res. 44, 3410-3418. doi: 10.1016/j.watres.2010.03.017

Cole, J. R., Wang, Q., Cardenas, E., Fish, J., Chai, B., Farris, R. J., et al. (2009). The Ribosomal Database Project: improved alignments and new tools for rRNA analysis. Nucleic Acids Res. 37, D141-D145. doi: 10.1093/nar/g kn879

Dang, H. Y., and Lovell, C. R. (2016). Microbial surface colonization and biofilm development in marine environments. Microbiol. Mol. Biol. Rev. 80, 91-138. doi: $10.1128 / \mathrm{mmbr} .00037-15$

Edgar, R. C. (2010). Search and clustering orders of magnitude faster than BLAST. Bioinformatics 26, 2460-2461. doi: 10.1093/bioinformatics/btq461

Edgar, R. C., Haas, B. J., Clemente, J. C., Quince, C., and Knight, R. (2011). UCHIME improves sensitivity and speed of chimera detection. Bioinformatics 27, 2194-2200. doi: 10.1093/bioinformatics/btr381

Eiler, A., Langenheder, S., Bertilsson, S., and Tranvik, L. J. (2003). Heterotrophic bacterial growth efficiency and community structure at different natural organic carbon concentrations. Appl. Environ. Microbiol. 69, 3701-3709. doi: 10.1128/aem.69.7.3701-3709.2003

Feng, L., Liu, S., Wu, W., Ma, J., Li, P., Xu, H., et al. (2016). Dominant genera of cyanobacteria in Lake Taihu and their relationships with environmental factors. J. Microbiol. 54, 468-476. doi: 10.1007/s12275-016-6037-4

Fonseca, A. C., Summers, R. S., and Hernandez, M. T. (2001). Comparative measurements of microbial activity in drinking water biofilters. Water Res. 35, 3817-3824. doi: 10.1016/s0043-1354(01)00104-x

Gardoni, D., Vailati, A., and Canziani, R. (2012). Decay of ozone in water: a review. Ozone Sci. Eng. 34, 233-242. doi: 10.1080/01919512.2012.686354

Glöckner, F. O., Zaichikov, E., Belkova, N., Denissova, L., Pernthaler, J., Pernthaler, A., et al. (2000). Comparative 16S rRNA analysis of lake bacterioplankton reveals globally distributed phylogenetic clusters including an abundant group of actinobacteria. Appl. Environ. Microbiol. 66, 5053-5065. doi: 10.1128/aem.66.11.5053-5065.2000 
Gomez-Alvarez, V., Revetta, R. P., and Domingo, J. W. S. (2012). Metagenomic analyses of drinking water receiving different disinfection treatments. Appl. Environ. Microbiol. 78, 6095-6102. doi: 10.1128/aem.01018-12

Hayes-Larson, E. L., and Mitch, W. A. (2010). Influence of the method of reagent addition on dichloroacetonitrile formation during chloramination. Environ. Sci. Technol. 44, 700-706. doi: 10.1021/es9025112

Hedegaard, M. J., and Albrechtsen, H. J. (2014). Microbial pesticide removal in rapid sand filters for drinking water treatment-potential and kinetics. Water Res. 48, 71-81. doi: 10.1016/j.watres.2013.09.024

Hirai, J., Nagai, S., and Hidaka, K. (2017). Evaluation of metagenetic community analysis of planktonic copepods using Illumina MiSeq: comparisons with morphological classification and metagenetic analysis using Roche 454. PLoS ONE 12:e0181452. doi: 10.1371/journal.pone.0181452

Holinger, E. P., Ross, K. A., Robertson, C. E., Stevens, M. J., Harris, J. K., and Pace, N. R. (2014). Molecular analysis of point-of-use municipal drinking water microbiology. Water Res. 49, 225-235. doi: 10.1016/j.watres.2013.11.027

Hunt, N. K., and Marinas, B. J. (1999). Inactivation of Escherichia coli with ozone: chemical and inactivation kinetics. Water Res. 33, 2633-2641. doi: 10.1016/s0043-1354(99)00115-3

Hutalle-Schmelzer, K. M., Zwirnmann, E., Krüeger, A., and Grossart, H. P. (2010). Enrichment and cultivation of pelagic bacteria from a humic lake using phenol and humic matter additions. FEMS Microbiol. Ecol. 72, 58-73. doi: 10.1111/j.1574-6941.2009.00831.x

Kim, T. G., Yun, J., Hong, S. H., and Cho, K. S. (2014). Effects of water temperature and backwashing on bacterial population and community in a biological activated carbon process at a water treatment plant. Appl. Microbiol. Biotechnol. 98, 1417-1427. doi: 10.1007/s00253-013-5057-9

Kim, T. S., Jeong, J. Y., Wells, G. F., and Park, H. D. (2013). General and rare bacterial taxa demonstrating different temporal dynamic patterns in an activated sludge bioreactor. Appl. Microbiol. Biotechnol. 97, 1755-1765. doi: $10.1007 /$ s00253-012-4002-7

Langille, M. G., Zaneveld, J., Caporaso, J. G., McDonald, D., Knights, D., Reyes, J. A., et al. (2013). Predictive functional profiling of microbial communities using 16S rRNA marker gene sequences. Nat. Biotechnol. 31, 814-821. doi: $10.1038 /$ nbt.2676

LaPara, T. M., Wilkinson, K., Strait, J. M., Hozalski, R. M., Sadowksy, M. J., and Hamilton, M. J. (2015). The bacterial communities of full-scale biologically active, granular activated carbon filters are stable and diverse and potentially contain novel ammonia-oxidizing microorganisms. Appl. Environ. Microbiol. 81, 6864-6872. doi: 10.1128/aem.01692-15

Lautenschlager, K., Hwang, C., Ling, F., Liu, W. T., Boon, N., Köster, O., et al. (2014). Abundance and composition of indigenous bacterial communities in a multi-step biofiltration-based drinking water treatment plant. Water Res. 62, 40-52. doi: 10.1016/j.watres.2014.05.035

Lautenschlager, K., Hwang, C., Liu, W. T., Boon, N., Köster, O., Vrouwenvelder, H., et al. (2013). A microbiology-based multi-parametric approach towards assessing biological stability in drinking water distribution networks. Water Res. 47, 3015-3025. doi: 10.1016/j.watres.2013.03.002

Lee, J., and Deininger, R. A. (2000). Survival of bacteria after ozonation. Ozone Sci. Eng. 22, 65-75. doi: 10.1080/01919510008547229

Lee, S. H., Kang, H. J., and Park, H. D. (2015). Influence of influent wastewater communities on temporal variation of activated sludge communities. Water Res. 73, 132-144. doi: 10.1016/j.watres.2015.01.014

LeLacheur, R. M., and Glaze, W. H. (1996). Reactions of ozone and hydroxyl radicals with serine. Environ. Sci. Technol. 30, 1072-1080. doi: $10.1021 /$ es940544z

Li, C., Ling, F., Zhang, M., Liu, W. T., Li, Y., and Liu, W. (2017). Characterization of bacterial community dynamics in a full-scale drinking water treatment plant. J. Environ. Sci. 51, 21-30. doi: 10.1016/j.jes.2016.05.042

Li, X., Upadhyaya, G., Yuen, W., Brown, J., Morgenroth, E., and Raskin, L. (2010). Changes in the structure and function of microbial communities in drinking water treatment bioreactors upon addition of phosphorus. Appl. Environ. Microbiol. 76, 7473-7481. doi: 10.1128/aem.01232-10.

Li, Y. P., Tang, C. Y., Yu, Z. B., and Acharya, K. (2014). Correlations between algae and water quality: factors driving eutrophication in Lake Taihu, China. Int. J. Environ. Sci. Technol. 11, 169-182. doi: 10.1007/s13762-013-0436-4.

Liao, X., Chen, C., Wang, Z., Wan, R., Chang, C.-H., Zhang, X., et al. (2013). Pyrosequencing analysis of bacterial communities in drinking water biofilters receiving influents of different types. Process Biochem. 48, 703-707. doi: $10.1016 /$ j.procbio.2013.02.033

Lin, W., Yu, Z., Zhang, H., and Thompson, I. P. (2014). Diversity and dynamics of microbial communities at each step of treatment plant for potable water generation. Water Res. 52, 218-230. doi: 10.1016/j.watres.2013.10.071

Lindstrom, E. S. (2000). Bacterioplankton community composition in five lakes differing in trophic status and humic content. Microb. Ecol. 40, 104-113. doi: 10.1007/s002480000036

Loman, N. J., Misra, R. V., Dallman, T. J., Constantinidou, C., Gharbia, S. E., Wain, J., et al. (2012). Performance comparison of benchtop high-throughput sequencing platforms. Nat. Biotechnol. 30, 434-439. doi: 10.1038/nbt.2198

Lu, X. M., Chen, C., and Zheng, T. L. (2017). Metagenomic insights into effects of chemical pollutants on microbial community composition and function in estuarine sediments receiving polluted river water. Microb. Ecol. 73, 791-800. doi: 10.1007/s00248-016-0868-8

Lurling, M., Eshetu, F., Faassen, E. J., Kosten, S., and Huszar, V. L. M. (2013). Comparison of cyanobacterial and green algal growth rates at different temperatures. Freshw. Biol. 58, 552-559. doi: 10.1111/j.1365-2427.2012.02866.x

Martiny, A. C., Albrechtsen, H. J., Arvin, E., and Molin, S. (2005). Identification of bacteria in biofilm and bulk water samples from a nonchlorinated model drinking water distribution system: detection of a large nitrite-oxidizing population associated with Nitrospira spp. Appl. Environ. Microbiol. 71, 8611-8617. doi: 10.1128/aem.71.12.8611-8617.2005

Mi, Z., Dai, Y., Xie, S., Chen, C., and Zhang, X. (2015). Impact of disinfection on drinking water biofilm bacterial community. J. Environ. Sci. 37, 200-205. doi: 10.1016/j.jes.2015.04.008

Mir, J., Morató, J., and Ribas, F. (1997). Resistance to chlorine of freshwater bacterial strains. J. Appl. Microbiol. 82, 7-18. doi: 10.1111/j.1365-2672.1997.tb03292.x

Nazarian, E. J., Bopp, D. J., Saylors, A., Limberger, R. J., and Musser, K. A. (2008). Design and implementation of a protocol for the detection of Legionella in clinical and environmental samples. Diagn. Microbiol. Infect. Dis. 62, 125-132. doi: 10.1016/j.diagmicrobio.2008.05.004

Newton, R. J., Jones, S. E., Eiler, A., McMahon, K. D., and Bertilsson, S. (2011). A guide to the natural history of freshwater lake bacteria. Microbiol. Mol. Biol. Rev. 75, 14-49. doi: 10.1128/mmbr.00028-10

Noyce, G. L., Fulthorpe, R., Gorgolewski, A., Hazlett, P., Honghi, T., and Basiliko, N. (2016). Soil microbial responses to wood ash addition and forest fire in managed Ontario forests. Appl. Soil Ecol. 107, 368-380. doi: 10.1016/j.apsoil.2016.07.006

Pang, Y. C., Xi, J. Y., Xu, Y., Huo, Z. Y., and Hu, H. Y. (2016). Shifts of live bacterial community in secondary effluent by chlorine disinfection revealed by Miseq high-throughput sequencing combined with propidium monoazide treatment. Appl. Microbiol. Biotechnol. 100, 6435-6446. doi: 10.1007/s00253-016-7452-5

Parfenova, V. V., Gladkikh, A. S., and Belykh, O. I. (2013). Comparative analysis of biodiversity in the planktonic and biofilm bacterial communities in Lake Baikal. Microbiology 82, 91-101. doi: 10.1134/s0026261713010128

Pinto, A. J., Xi, C., and Raskin, L. (2012). Bacterial community structure in the drinking water microbiome is governed by filtration processes. Environ. Sci. Technol. 46, 8851-8859. doi: 10.1021/es302042t

Prest, E. I., Hammes, F., van Loosdrecht, M. C., and Vrouwenvelder, J. S. (2016). Biological stability of drinking water: controlling factors, methods, and challenges. Front. Microbiol. 7:45. doi: 10.3389/fmicb.2016.00045

Proctor, C. R., and Hammes, F. (2015). Drinking water microbiology from measurement to management. Curr. Opin. Biotechnol. 33, 87-94. doi: 10.1016/j.copbio.2014.12.014

Qin, Y. Y., Li, D. T., and Yang, H. (2007). Investigation of total bacterial and ammonia-oxidizing bacterial community composition in a full-scale aerated submerged biofilm reactor for drinking water pretreatment in China. FEMS Microbiol. Lett. 268, 126-134. doi: 10.1111/j.1574-6968.2006. 00571.x

Radomski, N., Lucas, F. S., Moilleron, R., Cambau, E., Haenn, S., and Moulin, L. (2010). Development of a real-time qPCR method for detection and enumeration of Mycobacterium spp. in surface water. Appl. Environ. Microbiol. 76, 7348-7351. doi: 10.1128/AEM.00942-10

Schloss, P. D., Westcott, S. L., Ryabin, T., Hall, J. R., Hartmann, M., Hollister, E. B., et al. (2009). Introducing mothur: open-source, platformindependent, community-supported software for describing and comparing 
microbial communities. Appl. Environ. Microbiol. 75, 7537-7541. doi: 10.1128/aem.01541-09

Schmeisser, C., Stöckigt, C., Raasch, C., Wingender, J., Timmis, K. N., Wenderoth, D. F., et al. (2003). Metagenome survey of biofilms in drinking-water networks. Appl. Environ. Microbiol. 69, 7298-7309. doi: 10.1128/aem.69.12.7298-7309.2003

Schmieder, R., and Edwards, R. (2011). Quality control and preprocessing of metagenomic datasets. Bioinformatics 27, 863-864. doi: 10.1093/bioinformatics/ btr026

Servais, P., Billen, G., and Bouillot, P. (1994). Biological colonization of granular activated carbon filters in drinking-water treatment. J. Environ. Eng. 120, 888-899. doi: 10.1061/(asce)0733-9372(1994)120:4(888)

Shu, D., He, Y., Yue, H., and Wang, Q. (2016). Metagenomic and quantitative insights into microbial communities and functional genes of nitrogen and iron cycling in twelve wastewater treatment systems. Chem. Eng. J. 290, 21-30. doi: 10.1016/j.cej.2016.01.024

Simoes, L. C., and Simoes, M. (2013). Biofilms in drinking water: problems and solutions. RSC Adv. 3, 2520-2533. doi: 10.1039/c2ra22243d

Sinclair, L., Osman, O. A., Bertilsson, S., and Eiler, A. (2015). Microbial vommunity vomposition and diversity via 16S rRNA gene amplicons: evaluating the Illumina platform. PLoS ONE 10:116955. doi: 10.1371/journal.pone.0116955

Smith, D. P., and Peay, K. G. (2014). Sequence depth, not PCR replication, improves ecological inference from next generation DNA sequencing. PLoS ONE 9:90234. doi: 10.1371/journal.pone.0090234

Staley, C., Gould, T. J., Wang, P., Phillips, J., Cotner, J. B., and Sadowsky, M. J. (2015). Species sorting and seasonal dynamics primarily shape bacterial communities in the Upper Mississippi River. Sci. Total Environ. 505, 435-445. doi: 10.1016/j.scitotenv.2014.10.012

Stanish, L. F., Hull, N. M., Robertson, C. E., Harris, J. K., Stevens, M. J., Spear, J. R., et al. (2016). Factors influencing bacterial diversity and community composition in municipal drinking waters in the Ohio River Basin, USA. PLoS ONE 11:e157966. doi: 10.1371/journal.pone.0157966

Stewart, M. H., Wolfe, R. L., and Means, E. G. (1990). Assessment of the bacteriological activity associated with granular ativated carbon treatment of drinking water. Appl. Environ. Microbiol. 56, 3822-3829.

Suzuki, M. T., Taylor, L. T., and DeLong, E. F. (2000). Quantitative analysis of small-subunit rRNA genes in mixed microbial populations via 5'-nuclease assays. Appl. Environ. Microbiol. 66, 4605-4614. doi: 10.1128/aem.66.11.4605-4614.2000

Tan, B., Ng, C., Nshimyimana, J. P., Loh, L. L., Gin, K. Y. H., and Thompson, J. R. (2015). Next-generation sequencing (NGS) for assessment of microbial water quality: current progress, challenges, and future opportunities. Front. Microbiol. 6:1027. doi: 10.3389/fmicb.2015.01027

Taylor, R. H., Falkinham, J. O., Norton, C. D., and LeChevallier, M. W. (2000). Chlorine, chloramine, chlorine dioxide, and ozone susceptibility of Mycobacterium avium. Appl. Environ. Microbiol. 66, 1702-1705. doi: 10.1128/aem.66.4.1702-1705.2000

Thomas, M. K., and Litchman, E. (2016). Effects of temperature and nitrogen availability on the growth of invasive and native cyanobacteria. Hydrobiologia 763, 357-369. doi: 10.1007/s10750-015-2390-2

Unno, T. (2015). Bioinformatic suggestions on MiSeq-based microbial community analysis. J. Microbiol. Biotechnol. 25, 765-770. doi: 10.4014/jmb.1409.09057

Vaerewijck, M. J., Huys, G., Palomino, J. C., Swings, J., and Portaels, F. (2005). Mycobacteria in drinking water distribution systems: ecology and significance for human health. Fems Microbiol. Rev. 29, 911-934. doi: 10.1016/j.femsre. 2005.02.001

Wang, H., Masters, S., Edwards, M. A., Falkinham, J. O. III, and Pruden, A. (2014). Effect of disinfectant, water age, and pipe materials on bacterial and eukaryotic community structure in drinking water biofilm. Environ. Sci. Technol. 48, 1426-1435. doi: 10.1021/es402636u

Wu, X., Xi, W. Y., Ye, W. J., and Yang, H. (2007). Bacterial community composition of a shallow hypertrophic freshwater lake in China, revealed by $16 \mathrm{~S}$ rRNA gene sequences. FEMS Microbiol. Ecol. 61, 85-96. doi: 10.1111/j.1574-6941.2007.00326.x

Xu, J., Tang, W., Ma, J., and Wang, H. (2017). Comparison of microbial community shifts in two parallel multi-step drinking water treatment processes. Appl. Microbiol. Biotechnol. 101, 5531-5541. doi: 10.1007/s00253-0178258-9

Yang, B. M., Liu, J. K., Chien, C. C., Surampalli, R. Y., and Kao, C. M. (2011). Variations in AOC and microbial diversity in an advanced water treatment plant. J. Hydrol. 409, 225-235. doi: 10.1016/j.jhydrol.2011. 08.022

Yang, J. X., Ma, J., Song, D., Zhai, X. D., and Kong, X. J. (2016). Impact of preozonation on the bioactivity and biodiversity of subsequent biofilters under low temperature conditions-A pilot study. Front. Env. Sci. Eng. 10:5. doi: 10.1007/s11783-016-0844-z

Yu, S., Lin, T., and Chen, W. (2014). Photocatalytic inactivation of particleassociated Escherichia coli using $\mathrm{UV} / \mathrm{TiO}_{2}$. RSC Adv. 4, 31370-31377. doi: 10.1039/C4RA04061A

Zeng, D. N., Fan, Z. Y., Chi, L., Wang, X., Qu, W. D., and Quan, Z. X. (2013). Analysis of the bacterial communities associated with different drinking water treatment processes. World J. Microbiol. Biotechnol. 29, 1573-1584. doi: 10.1007/s11274-013-1321-5

Zhang, Y., Li, P., and Zhou, L. (2015). Study on the release of HPC and particles in ozonation and biological activated carbon processes. Chem. Eng. J. 276, 37-43. doi: 10.1016/j.cej.2015.04.062

Zhang, Y., Love, N., and Edwards, M. (2009). Nitrification in drinking water systems. Crit. Rev. Environ. Sci. Technol. 39, 153-208. doi: 10.1080/10643380701631739

Zwart, G., Crump, B. C., Agterveld, M., Hagen, F., and Han, S. K. (2002). Typical freshwater bacteria: an analysis of available 16S rRNA gene sequences from plankton of lakes and rivers. Aquat. Microb. Ecol. 28, 141-155. doi: 10.3354/ame028141

Zwirglmaier, K., Keiz, K., Engel, M., Geist, J., and Raeder, U. (2015). Seasonal and spatial patterns of microbial diversity along a trophic gradient in the interconnected lakes of the Osterseen Lake District, Bavaria. Front. Microbiol. 6:1168. doi: $10.3389 /$ fmicb. 2015.01168

Conflict of Interest Statement: The authors declare that the research was conducted in the absence of any commercial or financial relationships that could be construed as a potential conflict of interest.

Copyright (C) $2017 \mathrm{Li}, \mathrm{Yu}, \mathrm{Li}, \mathrm{Liu}, \mathrm{Gu}, \mathrm{Liu}, \mathrm{Liu}, \mathrm{Ye}, \mathrm{Xia}$ and Ren. This is an open-access article distributed under the terms of the Creative Commons Attribution License (CC $B Y)$. The use, distribution or reproduction in other forums is permitted, provided the original author(s) or licensor are credited and that the original publication in this journal is cited, in accordance with accepted academic practice. No use, distribution or reproduction is permitted which does not comply with these terms. 